\title{
Expanding the Goddard CSH Algorithm for GPM: New Extratropical Retrievals
}

\author{
W.-K. TAO \\ Mesoscale Atmospheric Processes Laboratory, NASA/Goddard Space Flight Center, Greenbelt, Maryland \\ T. IGUCHI \\ Mesoscale Atmospheric Processes Laboratory, NASA/Goddard Space Flight Center, Greenbelt, and Earth System \\ Science Interdisciplinary Center, University of Maryland, College Park, College Park, Maryland
}

\section{S. LANG}

Mesoscale Atmospheric Processes Laboratory, NASA/Goddard Space Flight Center, Greenbelt, and Science Systems and Applications, Inc., Lanham, Maryland

(Manuscript received 22 August 2018, in final form 6 February 2019)

\begin{abstract}
The Goddard convective-stratiform heating $(\mathrm{CSH})$ algorithm has been used to retrieve latent heating $(\mathrm{LH})$ associated with clouds and cloud systems in support of the Tropical Rainfall Measuring Mission and Global Precipitation Measurement (GPM) mission. The CSH algorithm requires the use of a cloud-resolving model to simulate LH profiles to build lookup tables (LUTs). However, the current LUTs in the CSH algorithm are not suitable for retrieving LH profiles at high latitudes or winter conditions that are needed for GPM. The NASA Unified-Weather Research and Forecasting (NU-WRF) Model is used to simulate three eastern continental U.S. (CONUS) synoptic winter and three western coastal/offshore events. The relationship between LH structures (or profiles) and other precipitation properties (radar reflectivity, freezing-level height, echo-top height, maximum $\mathrm{dB} Z$ height, vertical $\mathrm{dB} Z$ gradient, and surface precipitation rate) is examined, and a new classification system is adopted with varying ranges for each of these precipitation properties to create LUTs representing high latitude/winter conditions. The performance of the new LUTs is examined using a self-consistency check for one CONUS and one West Coast offshore event by comparing LH profiles retrieved from the LUTs using model-simulated precipitation properties with those originally simulated by the model. The results of the self-consistency check validate the new classification and LUTs. The new LUTs provide the foundation for high-latitude retrievals that can then be merged with those from the tropical CSH algorithm to retrieve LH profiles over the entire GPM domain using precipitation properties retrieved from the GPM combined algorithm.
\end{abstract}

\section{Introduction}

Rainfall production is a fundamental process within Earth's hydrological cycle because it represents a principal forcing term in surface water budgets, and its energetics corollary, latent heating $(\mathrm{LH})$, is also one of the principal sources of atmospheric diabatic heating. Latent heating (or cooling) results from phase changes of water; it consists of condensation/evaporation (vaporliquid phases), deposition/sublimation (vapor-solid phases), and freezing/melting (solid-liquid phases).

\footnotetext{
Corresponding author: Dr. Wei-Kuo Tao, wei-kuo.tao-1@ nasa.gov
}

LH and its vertical distribution not only have a strong influence on a variety of tropical circulations, including tropical waves and tropical cyclone intensity, but also on midlatitude cyclones and weather systems. Moreover, the processes associated with $\mathrm{LH}$ result in significant nonlinear changes in atmospheric radiation through the creation, dissipation, and modulation of clouds and precipitation. Although more recent efforts have been made to estimate the LH associated with weakly precipitating, mostly warm rain cloud systems that are detectable using CloudSat (Nelson et al. 2016; Nelson and L'Ecuyer 2018; Huaman and Schumacher 2018), the vast majority of rain and hence LH in the tropics comes from more intense rain associated with 
TABLE 1. Summary of the SLH and CSH algorithms. Note the conventional relationship between $Q_{1}$ (apparent heat source), LH (latent heating), and $Q_{R}$ (radiative heating) is expressed by $Q_{1}-Q_{R}=\mathrm{LH}+$ EHT, where the final term represents eddy heat transport by clouds (note that vertically integrated EHT is 0; i.e., it provides no explicit influence on surface rainfall). CSH and SLH use CRM-simulated profiles in their lookup tables explicitly.

\begin{tabular}{lll}
\hline \hline & \multicolumn{1}{c}{ SLH } & \multicolumn{1}{c}{ CSH } \\
\hline $\begin{array}{l}\text { Key references } \\
\text { Cases }\end{array}$ & Shige et al. (2004, 2007, 2008, 2009) & Tao et al. (1993, 2000, 2001, 2010), Lang and Tao (2018) \\
& Tropics: TOGA COARE & Tropics: 10 field campaigns (4 land; 6 ocean) \\
Input & Winter: 6 oceanic events & Winter: 6 events (land and oceanic) \\
Products & PR/DPR & Combined algorithm \\
& LH; $\mathrm{Q}_{1 R} ; \mathrm{Q}_{2}$ & $\begin{array}{c}\text { Tropics: } \mathrm{LH}, Q_{R}, \mathrm{Q}_{2} \text {, and eddy heating and moistening; } \\
\text { poleward of } 37^{\circ} \mathrm{N} / \mathrm{S}: \text { LH only }\end{array}$ \\
Lookup tables & No horizontal eddy; based on CRM domain and time & Combined horizontal and vertical eddy; CRM domain \\
& $(5$ min) averaged (no subset): consistent with & sampled on 32-km $(64 \mathrm{~km})$ model subdomains for \\
& surface rainfall & GPM (TRMM) $0.25^{\circ} \times 0.25^{\circ}\left(0.5^{\circ} \times 0.5^{\circ}\right)$ gridded \\
& & products \\
\hline
\end{tabular}

deeper convective clouds and convective cloud systems that were largely detectable (Berg et al. 2010) by the Tropical Rainfall Measuring Mission (TRMM, launched in 1997) Precipitation Radar (PR). Therefore, LH has long been a standard product for both TRMM and the follow-on Global Precipitation Measurement (GPM, launched in 2014) mission. The TRMM PR, GPM DualFrequency Precipitation Radar (DPR), TRMM microwave imager (TMI), and GPM microwave imager (GMI) can all be used to retrieve rain rates as well as estimate their convective/stratiform components. Rainfall products from TRMM/GPM thus provide the essential data needed to retrieve profiles of cloud LH.

Since LH cannot be measured directly, LH profiles simulated using cloud-resolving models (CRMs) are regularly used to build lookup tables (LUTs) for LH retrieval algorithms (see the review papers by Tao et al. 2006, 2016a). Currently, two different LH algorithms, the Goddard convective-stratiform heating $(\mathrm{CSH})$ and the Japanese spectral latent heating (SLH), are being used to produce standard LH products for both the TRMM and GPM periods. Table 1 shows the key references, inputs, CRM-simulated cases, and the LUTs used in the CSH and SLH algorithms. The CSH- and SLHretrieved products ( $\mathrm{LH}$, radiation $Q_{R}$, apparent moisture sink $Q_{2}$, and eddy transport) are also shown in the table. Note that intensive rawinsonde networks can be used to obtain vertical profiles of the apparent heat source $Q_{1}$ (see Yanai et al. 1973), which is equivalent to the sum of $\mathrm{LH}$, radiation and eddy heat transport. Further details on the CSH and SLH algorithms are presented in section 2.

The LH LUTs used in the current CSH algorithm are based on CRM simulations associated with precipitation systems over the tropics or in the warm season (Tao et al. 2010; Lang and Tao 2018). Simulations of precipitation systems occurring at higher latitudes (poleward of $35^{\circ} \mathrm{N} / \mathrm{S}$ ) and in the winter season are needed for GPM. The main objective of paper is to describe the development and performance of a new Goddard LH algorithm for high latitudes and winter conditions. A brief review of the CSH algorithm, its differences with SLH and their standard products are described in section 2 . The model and simulated cases are described in section 3 . The latent heating algorithm and its LUT are discussed in section 4. In section 5, a self-consistency check of the LH algorithm is presented, and a summary is given in section 6 .

\section{LH algorithms and standard LH products}

TRMM was launched in November 1997 with the underlying goal of obtaining accurate four-dimensional estimates of rainfall and $\mathrm{LH}$ over the global tropics and subtropics equatorward of $35^{\circ}$. In addition to the $\mathrm{CSH}$ and SLH algorithms, several other algorithms were also developed that could be used to retrieve $\mathrm{LH}$ from satellite data, including the trained radiometer (TRAIN; Grecu and Olson 2006; Grecu et al. 2009), hydrometeor heating (HH; Yang and Smith 1999a,b, 2000), and Precipitation Radar heating (PRH; Satoh and Noda 2001) algorithms. Details on all of these algorithms, including their strengths and weaknesses and applications, were discussed in Tao et al. (2006) and Tao et al. (2016a). For the Goddard CSH algorithm, the TRMM/GPM combined (radar-radiometer) algorithmretrieved rainfall as well as precipitation properties passed down from the PR/DPR are used to retrieve profiles of LH. The Japan SLH algorithm uses $\mathrm{PR} / \mathrm{DPR}$-retrieved rainfall and precipitation properties to retrieve LH (Shige et al. 2007, 2008, 2009).

\section{a. The Goddard CSH algorithm}

Tao et al. (1990) used results from the Goddard Cumulus Ensemble model (GCE), a CRM, to develop a $\mathrm{LH}$ algorithm and was the first paper to estimate $\mathrm{LH}$ 
structures based on the vertical profiles of cloud hydrometeors. However, the algorithm requires artificial coefficients related to nonprecipitating cloud (cloud and cloud ice) to estimate condensation and deposition heating. LH profiles are quite different between the convective and stratiform regions (Houze 1982; Johnson 1984). Positive LH heating via condensation and deposition (and freezing) dominates throughout the column in the convective region. In the stratiform region, heating occurs above the melting level through deposition while cooling mainly from evaporation prevails beneath the melting level. Therefore, Tao et al. (1993) proposed a LH algorithm known as the CSH algorithm. It used a simple LUT consisting of rain-normalized $\mathrm{Q}_{1}$ profiles for the convective and stratiform region composited for land and ocean from sounding budgets and a few GCE simulations. The CSH algorithm's performance was tested through selfconsistency checking using GCE-simulated cloud heating data as "truth" (Tao et al. 2000), and the algorithm was used to retrieve LH structures using 1 month of TRMM rainfall products (Tao et al. 2001). Later, the CSH algorithm was redesigned and improved by using several GCE simulations and differentiating the LUTs into many bins and into separate heating components (Tao et al. 2010). In Tao et al. (2010), the number of LH profiles in the CSH LUTs (i.e., ocean and land) is greatly increased (approximately several hundred in each using 36 intensity and 20 stratiform bins) versus the previous version (i.e., Tao et al. 1993, 2000, 2001). Also, the profiles are binned according to mean conditional surface rain rates obtained from GCE model subdomains roughly consistent with the size of the CSH LH product grids (i.e., $32-\mathrm{km}$ model subdomains are used to build the LUTs for the TRMM half degree gridded products). This approach has several potential advantages regarding heating structures. Obviously, having many more profiles in the LUTs allows for the possibility of having many more heating structures, and using conditional rain rates allows for smaller areas of intense rain to be distinguished from larger areas of weak rain. Recently, the CSH algorithm was revised again (Lang and Tao 2018). In addition to conditional surface rain intensities and stratiform fraction, the land and ocean LUTs are further binned according to mean echo-top heights (five bins: $0-2,2-4,4-6,6-8$, and $8+\mathrm{km})$ and low-level ( $0-2 \mathrm{~km}$ AGL) vertical reflectivity gradients (downward increasing or decreasing) to improve the depth of heating and intensity of low-level evaporative cooling in stratiform regions, respectively. The GCE CRM database from which the CSH LUTs are derived was also upgraded with additional cases and the use of the improved Goddard 4-class ice (4ICE) scheme (Lang et al. 2014; Tao et al. 2016b) cloud microphysics (please see Lang and Tao 2018 for more details.).
TABLE 2. Evolution of the Goddard CSH algorithm with key improvements and references.

\begin{tabular}{ll}
\hline \hline \multicolumn{1}{c}{ Highlights } & Reference \\
\hline $\begin{array}{l}\text { First paper to use a CRM to develop } \\
\text { an LH algorithm-LH structure }\end{array}$ & Tao et al. (1990) \\
estimated from vertical hydrometeor & \\
profiles & \\
First paper on the CSH algorithm- & Tao et al. (1993) \\
composite both sounding-estimated & \\
and CRM-modeled convective and & \\
stratiform heating profiles into a & \\
simple LUT & \\
Examined the performance of the & Tao et al. (2000) \\
CSH algorithm using CRM- & \\
simulated (consistency check), & \\
SSM/I, and shipborne estimated & \\
rainfall and stratiform percentages; & \\
retrieved LH is sensitive to surface & \\
rainfall amount and stratiform & \\
percentage & \\
First paper to retrieve LH based on & Tao et al. (2001) \\
1 month of TRMM-estimated & \\
rainfall products & \\
Improved CSH by using several CRM & Tao et al. (2010) \\
simulations to build the LUTs, & \\
individual heating components are & \\
retrieved separately, and LUTs are & \\
separated into many surface rain rate & \\
intensity bins and stratiform fractions & \\
Improved CSH by using even more & Lang and Tao (2018) \\
CRM simulations with better & \\
microphysics at finer resolution to & \\
build the LUTs and added new & \\
metrics for echo-top heights and & \\
low-level dBZ gradients to the LUTs & \\
Expanded the retrieval of LH to & \\
higher latitudes and the cold season & \\
using NU-WRF simulations of synoptic & \\
storms to build separate LUTs & \\
Review papers on LH algorithms, & \\
applications, and evaluations & \\
\hline
\end{tabular}

The LUTs in the more recent versions of the CSH algorithm (Tao et al. 2010; Lang and Tao 2018) include separate CRM-generated $\mathrm{LH}$, eddy heating, and $Q_{R}$ at common levels and can thus be used to provide the eddy and radiative terms independent of other LH algorithm groups. Table 2 shows the highlights and evolution of the $\mathrm{CSH}$ algorithm, and Table 3 shows the field campaign data used to build the CSH algorithm's LUTs including the 1) Global Atmospheric Research Program's Atlantic Tropical Experiment (GATE), 2) South China Sea Monsoon Experiment/northern enhanced sounding array (SCSMEX/NESA), 3) Tropical Ocean Global Atmosphere Coupled Ocean-Atmosphere Response Experiment (TOGA COARE), 4) Kwajalein Experiment (KWAJEX), 5) Tropical Warm Pool-International Cloud Experiment (TWP-ICE), 6) Midlatitude Continental 
TABLE 3. GCE model-simulated cases used to build the CSH LUTs.

\begin{tabular}{|c|c|c|c|c|}
\hline Field campaign & Geographic location & Dates & $\begin{array}{l}\text { Modeling } \\
\text { days }\end{array}$ & Reference(s) \\
\hline ARM-SGP-97 & Land (Southern Great Plains) & June-July 1997 & 29 & $\begin{array}{l}\text { Tao et al. (2004); } \\
\text { Zeng et al. (2009) }\end{array}$ \\
\hline ARM-SGP-02 & Land (Southern Great Plains) & May-June 2002 & 20 & Zeng et al. $(2007 ; 2009)$ \\
\hline SCSMEX/NESA & Ocean (South China Sea) & May-June 1998 & 45 & $\begin{array}{l}\text { Tao et al. (2003), } \\
\text { Zeng et al. (2008) }\end{array}$ \\
\hline TOGA COARE & Ocean (equatorial western Pacific) & November 1992-February 1993 & 61 & $\begin{array}{l}\text { Das et al. (1999); } \\
\text { Johnson et al. (2002); } \\
\text { Zeng et al. (2009) }\end{array}$ \\
\hline GATE & Ocean (tropical Atlantic) & August - September 1974 & 20 & $\begin{array}{l}\text { Tao et al. (2004); } \\
\text { Zeng et al. (2009) }\end{array}$ \\
\hline KWAJEX & Ocean (Marshall Islands) & July-September 1999 & 52 & Zeng et al. (2008) \\
\hline TWP-ICE & Ocean (Darwin, Australia) & January-February 2006 & 24 & Zeng et al. (2013) \\
\hline MC3E & Land (Southern Great Plains) & April-March 2011 & 33 & Zeng et al. (2007) \\
\hline DYNAMO & Ocean (Equatorial Indian Ocean) & November-December 2011 & 31 & Li et al. (2018) \\
\hline GoAMAZON & Land (Amazon basin) & February-March 2014 & 40 & Lang and Tao (2018) \\
\hline
\end{tabular}

Convective Clouds Experiment (MC3E), 7) Dynamics of the MJO (DYNAMO), 8) Green Ocean Amazon Experiment (GoAMAZON), and 9) the U.S. Department of Energy's Atmospheric Radiation Measurement Southern Great Plains site (1997 and 2002). These field campaigns are used to provide large-scale advective tendencies in temperature and water vapor as forcing to drive GCE model simulations (Tao et al. 2010; Lang and Tao 2018) and results in the GCE-simulated rainfall, $Q_{1}$ and $Q_{2}$ always being in excellent agreement with the sounding estimated.

\section{b. Standard LH products}

There are two standard TRMM LH algorithms, the Goddard CSH and the Japanese SLH. Both depend upon CRM (i.e., GCE) simulations for their LUTs. The National Aeronautics and Space Administration-Japan Aerospace Exploration Agency (NASA-JAXA) joint science team initially recommended using the current TRMM CSH and SLH algorithms to produce GPM LH products over the same domain as TRMM at the beginning of July 2015. However, to cover the entire GPM domain the CSH and SLH algorithms will need to be able to retrieve LH structures (profiles) associated with high-latitude weather events (i.e., frontal, snow events). This requires expanding the LUTs and extending the algorithm for these types of weather events. For GPM, $\mathrm{CSH}$ and SLH standard products are to be produced at $0.25^{\circ} \times 0.25^{\circ}$ and with 80 vertical layers as compared with $0.5^{\circ} \times 0.5^{\circ}$ and 19 vertical layers for TRMM (see Table 4).

\section{c. Differences and similarities between SLH and CSH}

In both the SLH and CSH algorithms, a convective and stratiform separation is used because of the distinctive LH structures in each of those regions. Also, for both algorithms, the GCE is used to generate their LUTs. The differences and similarities as well as the references for the CSH and SLH algorithms are listed in Table 1.

In addition to how the LUTs are structured, there are three major differences between the CSH and SLH algorithms in terms of the CRM-simulated databases and their associated LUTs, input for retrieving LH, and the retrieved LH products. First, PR-derived (TRMM) and DPR-derived (GPM) rainfall and precipitation properties are used for SLH's input, whereas for the CSH algorithm retrieved rainfall from the TRMM and GPM versions of the combined algorithm is used as input with

TABLE 4. Summary of the CSH and SLH algorithms with retrieved products and salient references included. By convention, $Q_{1}-Q_{R}=\mathrm{LH}+\mathrm{EHT}$, where $Q_{R}$ is radiative heating and the final term represents eddy heat transport by clouds (vertically integrated EHT is zero and provides no explicit influence on surface rainfall). Note that orbital heating is not a standard PMM product.

\begin{tabular}{|c|c|c|c|c|}
\hline & Spatial Scale & Temporal Scale & Algorithm & Products \\
\hline Gridded & $\begin{array}{l}0.25^{\circ} \times 0.25^{\circ} \\
\quad 80 \text { vertical layers }\end{array}$ & Monthly & SLH-DPR; CSH-combined & $\mathrm{LH}, Q_{1}-Q_{R}, Q_{2} ; \mathrm{LH}, \mathrm{EHT}, Q_{R}, Q_{2}$ \\
\hline Orbital & $\begin{array}{l}\text { Pixel; } 80 \text { vertical } \\
\text { layers }\end{array}$ & Instantaneous & SLH-DPR; CSH-combined & LH, $Q_{1}-Q_{R}, Q_{2} ; \mathrm{LH}, \mathrm{EHT}, Q_{R}, Q_{2}$ \\
\hline Gridded orbital & $\begin{array}{l}0.25^{\circ} \times 0.25^{\circ} \\
\quad 80 \text { vertical layers }\end{array}$ & $\begin{array}{l}\text { Instantaneous with time } \\
\text { stamps on each grid }\end{array}$ & SLH-DPR; CSH-combined & LH, $Q_{1}-Q_{R}, Q_{2} ;$ LH, EHT, $Q_{R}, Q_{2}$ \\
\hline
\end{tabular}


additional precipitation properties passed through from the radars. Second, with SLH, the LH, $Q_{1 R}$ (or $Q_{1}-Q_{R}$ ), and $Q_{2}$ are retrieved; with the CSH algorithm, $Q_{R}$ is also retrieved (separately from $Q_{1 R}$ ) as well as the eddy transport for both heating and moistening. Last, the current SLH LUTs are based on four 9-day (10-18 December 1992, 27 December 1992-4 January 1993, 9-17 February 1993, and 18-26 February 1993) and one 8-day (19-26 December 1992) TOGA COARE 2D GCE simulations and six high-latitude oceanic cases over the Sea of Japan. On the other hand, the CSH algorithm CRM database has several multiweek tropical cases for both ocean and land (10 cases with 355 total days of 2D GCE model simulations; see Table 3) plus six new highlatitude synoptic weather simulations (presented in this paper). For tropical and warm-season retrievals, the $\mathrm{CSH}$ LUTs are based on the 10 2D GCE 4ICE simulations; whereas for higher-latitude and cold-season retrievals, the six new NASA Unified-Weather Research and Forecasting (NU-WRF) Model 4ICE simulations are used to generate the CSH LUTs (discussed in the flowing sections). CSH tropical/warm-season retrievals are then merged with extratropical/cold-season retrievals based on the height of the freezing level. ${ }^{1}$

\section{NU-WRF Model and cases}

The GCE has been used for semi-idealized and longer-term simulations constrained by large-scale forcing derived from sounding networks; the latter ensures its simulated $Q_{1}$ and $Q_{2}$ profiles are in excellent agreement with the corresponding sounding budget and is the main reason the GCE is used to build both the CSH and SLH LUTs. Large-scale advective forcing derived from sounding networks is unavailable for winter at high-latitudes and may not be suitable for the more complex frontal structures associated with midlatitude cyclones. Therefore, a regional scale numerical model such as the NU-WRF Model (PetersLidard et al. 2015) is used as it is better suited to handle precipitation systems associated with highlatitude frontal and snow events and cyclones than the GCE.

\section{a. NU-WRF}

NU-WRF is a modeling system integrating the National Center for Atmospheric Research (NCAR)

\footnotetext{
${ }^{1}$ If the mean freezing-level height is above $4 \mathrm{~km}$, then the tropical values are used. If the mean freezing-level height is below $3 \mathrm{~km}$, then the extratropical values are used. Between 3 and $4 \mathrm{~km}$, the values are averaged using a linear weighting between the tropical and extratropical values.
}

Advanced Research WRF (WRF-ARW; Skamarock et al. 2008) with multiple modeling components (e.g., physics packages) and datasets developed at NASA Goddard Space Flight Center. NU-WRF has been used to provide real-time forecasts for GPM field campaigns [e.g., MC3E, the Iowa Flood Studies (IFloodS), and the Integrated Precipitation and Hydrology Experiment (IPHEX)] as well as regional climate simulations over the continental United States (CONUS) (e.g., Iguchi et al. 2017; Lee et al. 2017; Tian et al. 2017). It has also been used to simulate a variety of precipitation systems in intensive field measurement campaigns [e.g., the Canadian CloudSat/CALIPSO Validation Programme (C3VP) (Shi et al. 2010; Iguchi et al. 2012a), the Light Precipitation Validation Experiment (LPVEx) (Iguchi et al. 2014), the NASA African Monsoon Multidisciplinary Analyses (NAMMA) (Shi et al. 2014; Zhang et al. 2017; Matsui et al. 2019), MC3E (Iguchi et al. 2012b; Tao et al. 2013, 2016b), and IFloodS (Wu et al. 2016)].

This study utilizes NU-WRF, version 8 patch 4 , which is based on NCAR WRF-ARW, version 3.7.1, together with the updated Goddard 4-ICE bulk microphysics scheme (Lang et al. 2014; Tao et al. 2016b) and the updated Goddard short- and longwave radiation schemes (Chou and Suarez 1999; Chou et al. 2001; Matsui and Jacob 2014) to conduct high-resolution (3-km inner nested domains) extratropical simulations. The Goddard broadband two-stream (upward and downward fluxes) approach is used for the short- and longwave radiative flux and atmospheric heating calculations and its explicit interactions with clouds (microphysics). The Mellor-Yamada-Janjić (Mellor and Yamada 1982) level 2 turbulence closure model is used for the planetary boundary layer parameterization through the full range of atmospheric turbulent regimes. The scheme was coded/modified by Dr. Janjić for the National Centers for Environmental Prediction (NCEP) Eta Model. Model terrain is smoothed from the $5-\mathrm{m}(\sim 5 \mathrm{~km})$ and 2-m $(\sim 4 \mathrm{~km})$ U.S. Geological Society terrain database for the two nested domains, respectively.

\section{b. Cases}

Six synoptic-scale storm cases are selected for the NUWRF simulations to generate the cold-season LH LUTs. Three cases are winter storms observed over the eastern CONUS in 2014 and 2015. The other three cases are storms that developed over the eastern Pacific Ocean off the coast of California during the CalWater 2015 field campaign (Ralph et al. 2016). Table 5 lists the dates of these six cases.

Of the three eastern CONUS winter storms, the first occurred on 16 March 2014. It was associated with a 
TABLE 5. Similar to Table 3, but for the NU-WRF-simulated cases used to build the CSH cold-season LUTs. The starting and ending times of the NU-WRF simulations are shown in the last two columns.

\begin{tabular}{lccc}
\hline \hline \multicolumn{1}{c}{ Cases } & Location & Simulation start time & End time \\
\hline Maritime winter storms & Eastern Pacific (off the & 0000 UTC 5 Feb 2015; 0000 UTC & 0000 UTC 7 Feb 2015; 0000 UTC \\
(CalWater2015) & coast of California) & 18 Feb 2015; 0000 UTC 15 Mar 2015 & 20 Feb 2015; 0000 UTC 17 Mar 2015 \\
$\begin{array}{l}\text { Continental synoptic } \\
\text { winter storms }\end{array}$ & Eastern CONUS & 0600 UTC 16 Mar 2014; 0000 UTC & 0600 UTC 17 Mar 2014; 1200 UTC \\
& & 16 Feb 2015; 0000 UTC 21 Feb 2015 & 17 Feb 2015; 1200 UTC 22 Feb 2015 \\
\hline
\end{tabular}

trailing cold front and brought snow to New Jersey. The second was a wintry precipitation event on 16-17 February 2015 that spread across the northern Gulf Coast states and then central Georgia and South Carolina before exiting off the North Carolina coast. The third case took place on 20-21 February 2015. Precipitation initially began as freezing rain and sleet for most of the area, except in the far northern sections of Missouri and into central Illinois, where it began as snow.

CalWater (Ralph et al. 2016) has managed a series of field campaigns along the U.S. West Coast to investigate clouds and precipitation, particularly in relation to atmospheric rivers (ARs). The 2015 field campaign occurred over January-March 2015 and captured several offshore AR events. The first case on 5 February 2015 developed offshore and was analyzed by Fairall et al. (2018). Synoptic-scale weak convective precipitation associated with a midlatitude frontal system approached the U.S. West Coast. The second case (18-19 February 2015) was similar to the first case, but the frontal system developed more offshore. The third case (15-16 March 2015) had an offshore frontal system with much weaker precipitation.

Figure 1 shows the geographical coverage of the model domains, which include sets of outer and innernested domains having horizontal grid spacings of 9 and $3 \mathrm{~km}$, respectively. The eastern CONUS domain (Fig. 1a) uses $695 \times 443 \times 61$ model grid points for the outer domain and $1129 \times 703 \times 61$ for the inner domain; the CalWater 2015 domains (Figs. 1b,c) employ $671 \times$ $582 \times 61$ and $685 \times 604 \times 61$ grid points. Time steps of 18 and $6 \mathrm{~s}$ were used in the outer and inner nested domains, respectively. The initial and lateral boundary conditions of the outer domains and the initial conditions for the inner domains come from NCEP final (FNL) operational global analysis data (Kalnay et al. 1996) with a grid spacing of $1^{\circ}$ in both latitude and longitude with 6-hourly intervals.

\section{NU-WRF simulations and simulated $\mathrm{LH}$ and radar reflectivity structures}

Hourly and $1 / 8^{\circ}$ precipitation data from the North American Land Data Assimilation System project, phase 2
(NLDAS-2; Xia et al. 2012), is used for comparison with the CONUS simulations. In general, the locations and patterns of the NU-WRF-simulated precipitation are in good agreement with observed for all three CONUS cases (Fig. 2). For example, the model captures the transition from narrow heavy rainbands associated with a convective line ahead of an advancing cold front in the Florida Panhandle to widespread weaker precipitation over North Carolina on the cold side of a frontal boundary that transitions to snow over Virginia fairly well in both organization and magnitude for the March 2016 case (Figs. 2a,d). For both February cases, the model also captures the precipitation location, organization, and intensity well (Figs. 2b,c,e,f). Both simulated and observed surface precipitation show a linear pattern oriented from southwest to northeast. The simulated high-precipitation region is located in western Georgia as observed for the 17 February case. For the February 21 case, the simulated high-precipitation region is near Tennessee and Kentucky and also in good agreement with the observed. However, the NU-WRFsimulated precipitation area generally is larger than the NLDAS-2 observed, especially over the northern sector of the system in all three cases.

The NLDAS- 2 rainfall products only cover the continental U.S. region. Therefore, the Integrated Multisatellite Retrievals for GPM (IMERG; resolution $0.1^{\circ}$ ) hourly precipitation products are used for comparison for the CalWater cases (Fig. 3). Overall, the location and pattern of the NU-WRF-simulated precipitation is in good agreement with observations for all three cases. For example, the model is able to replicate the location, orientation and linear nature of the AR event extending from the Northern California coast out into the open ocean for the 6 February case. And, for both the 19 February and 15 March cases, the model captures the location and basic pattern of the precipitation for these systems as shown by IMERG well off of the coast. There are also some discrepancies: most notably the lack of heavy rain along and just off shore of the Northern California coast in the 6 February case as well as an underestimation of rain coverage and amount near the western boundary in the 19 February case relative to IMERG. These deficiencies could be caused 

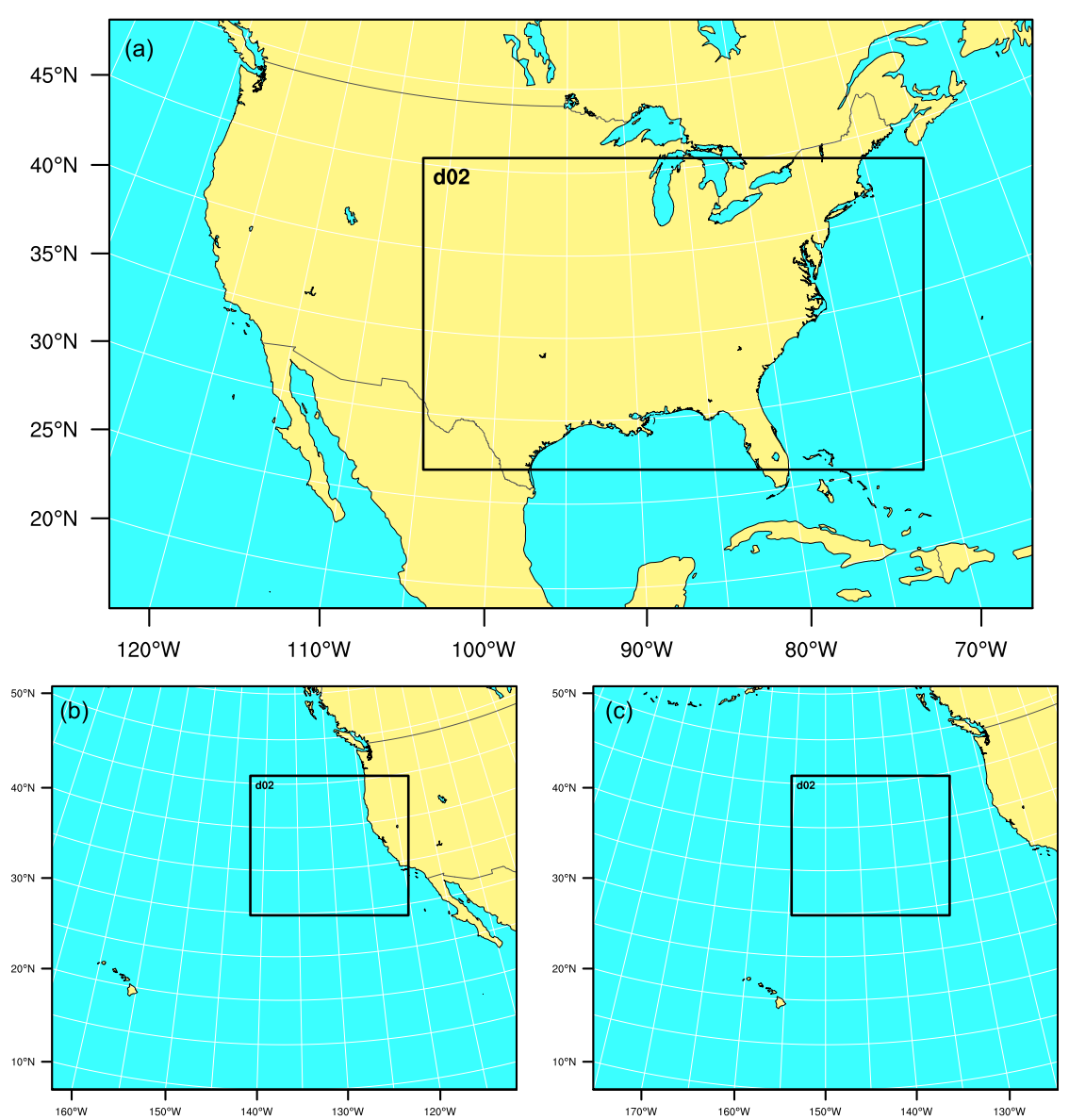

FIG. 1. Domain configurations of the NU-WRF simulations for the (a) three East Coast winter storms, (b) two CalWater2015 (5-6 Feb and 15-16 Mar) cases, and (c) one CalWater2015 (18-19 Feb) case. The outer maps correspond to the simulation domains with horizontal grid spacing of $9 \mathrm{~km}$, and the nested areas enclosed by black squares show the simulation domains with $3-\mathrm{km}$ grid spacing, the output of which is used to build the new CSH cold-season LH LUT.

by initial and/or boundary conditions, model physics, grid resolution or a combination thereof. Another simulation using dynamic nudging did not improve the simulated precipitation intensity or coverage for the 19 February case. Nevertheless, the NU-WRF simulations do capture some of the differences between these three cases as observed.

Figure 4 shows 12-hourly accumulated precipitation simulated from NU-WRF and estimated from IMERG for the CalWater cases. For the 6 February case, the results are similar to the 1-hourly with good overall agreement in pattern and amount expect for an underestimation in heavy rain off the coast of Northern California and midway along the AR near $\sim 34^{\circ}-35^{\circ} \mathrm{N}$. For the 19 February case, the NU-WRF-simulated 12-hourly accumulated precipitation is in better agreement with IMERG compared to the hourly precipitation comparison with more precipitation simulated farther away from the coast along the western boundary. In addition, the simulated precipitation shows areas of heavy accumulations there like IMERG; however, the amount and areal coverage of heavy rain is still too low relative to IMERG. There is no real change in the agreement for the 15 March case. Although the overall weaker nature of the event is consistent, rainfall still is lacking over the center of the domain relative to IMERG. For the CONUS cases, the 12-hourly accumulated precipitation for NU-WRF and NLDAS-2 are all very similar (not shown) as in the 1-h precipitation comparisons (Fig. 2).

Surface precipitation areal coverage $\left(>0.178 \mathrm{~mm} \mathrm{~h}^{-1}\right)$ is calculated for the three NU-WRF-simulated CalWater cases using the 12-hourly accumulations. The 6 February case has the largest $(55.6 \%)$ and the 15 March case the smallest $(0.3 \%)$ areal coverage, and the 19 February case has an intermediate value of $26.6 \%$. These results are consistent with those shown in Figs. 3 and 4 and are also 

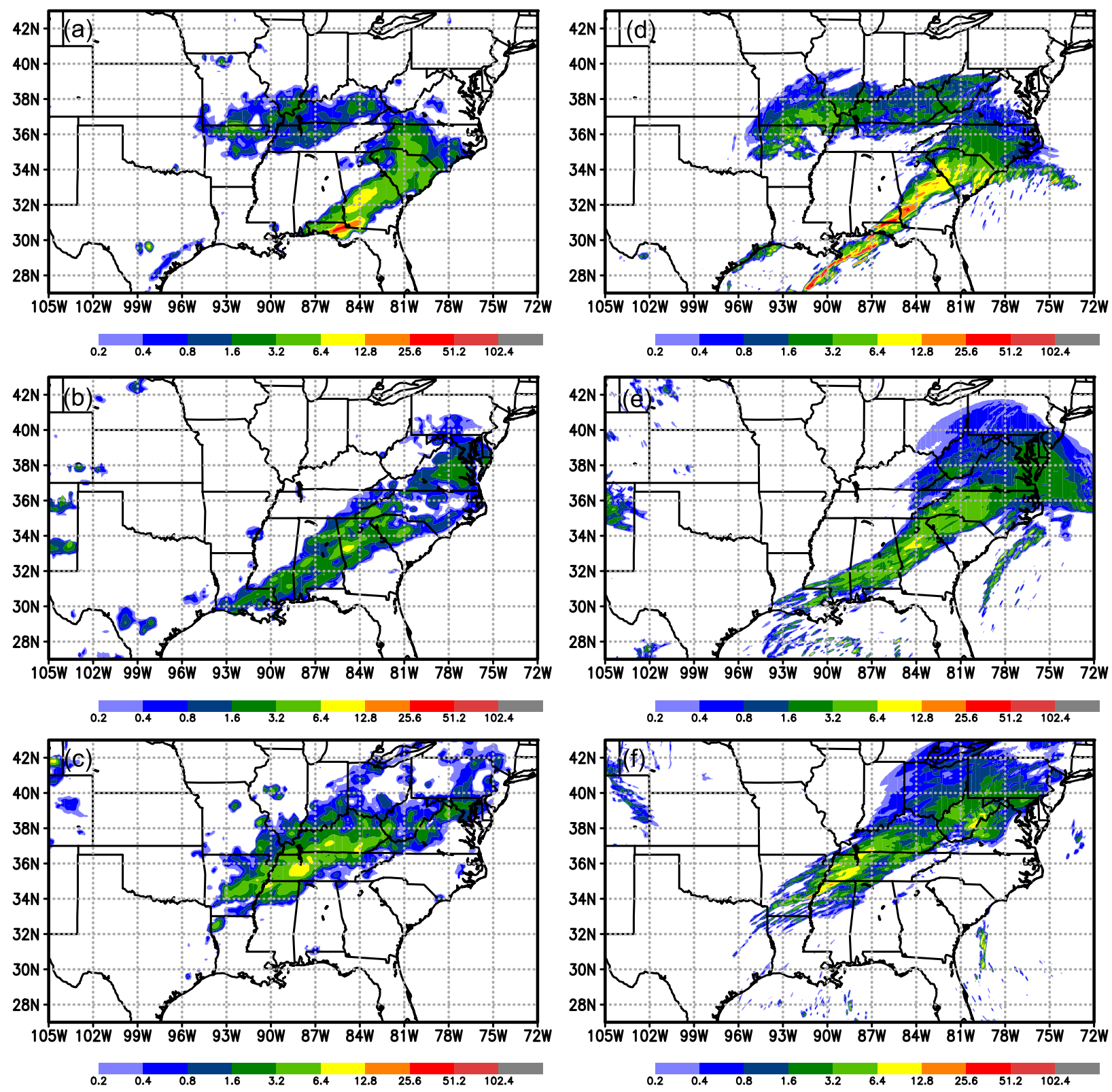

FIG. 2. Horizontal distributions of 1-h accumulated rainfall amounts for (a),(d) 1800-1900 UTC 16 Mar 2014, (b), (e) 0300-0400 UTC 17 Feb 2015, and (c),(f) 1800-1900 UTC 21 Feb 2015, derived from (left) NLDAS-2 Xia et al. 2012) "Forcing File A" and (right) the NU-WRF Model simulations.

consistent with the IMERG estimated values of $45.0 \%$, $31.1 \%$, and $0.3 \%$ for the 6 February, 19 February, and 15 March cases, respectively. Domain-average NU-WRFsimulated 12-h accumulated surface rainfall amounts are also calculated and compared with the IMERG estimated. The results are consistent with those for the areal coverage with the 6 February case having the most $(6.504 \mathrm{~mm})$ mean rainfall and the 15 March case the least $(0.274 \mathrm{~mm})$, with the 19 February case $(3.83 \mathrm{~mm})$ having an intermediate amount. These results are consistent with the IMERG estimated values of $7.323,5.501$, and $0.341 \mathrm{~mm}$ for the 6 February, 19 February, and 15 March cases, respectively, and confirm the apparent low bias shown in Fig. 4 for the 19 February case relative to IMERG.

The LH structures from these six cases, three continental and three oceanic events, will be used to construct the extratropical LUTs for the CSH algorithm (in additional to its tropical LUTs; see Lang and Tao 2018). The resolution of the GPM combined rainfall retrieval 

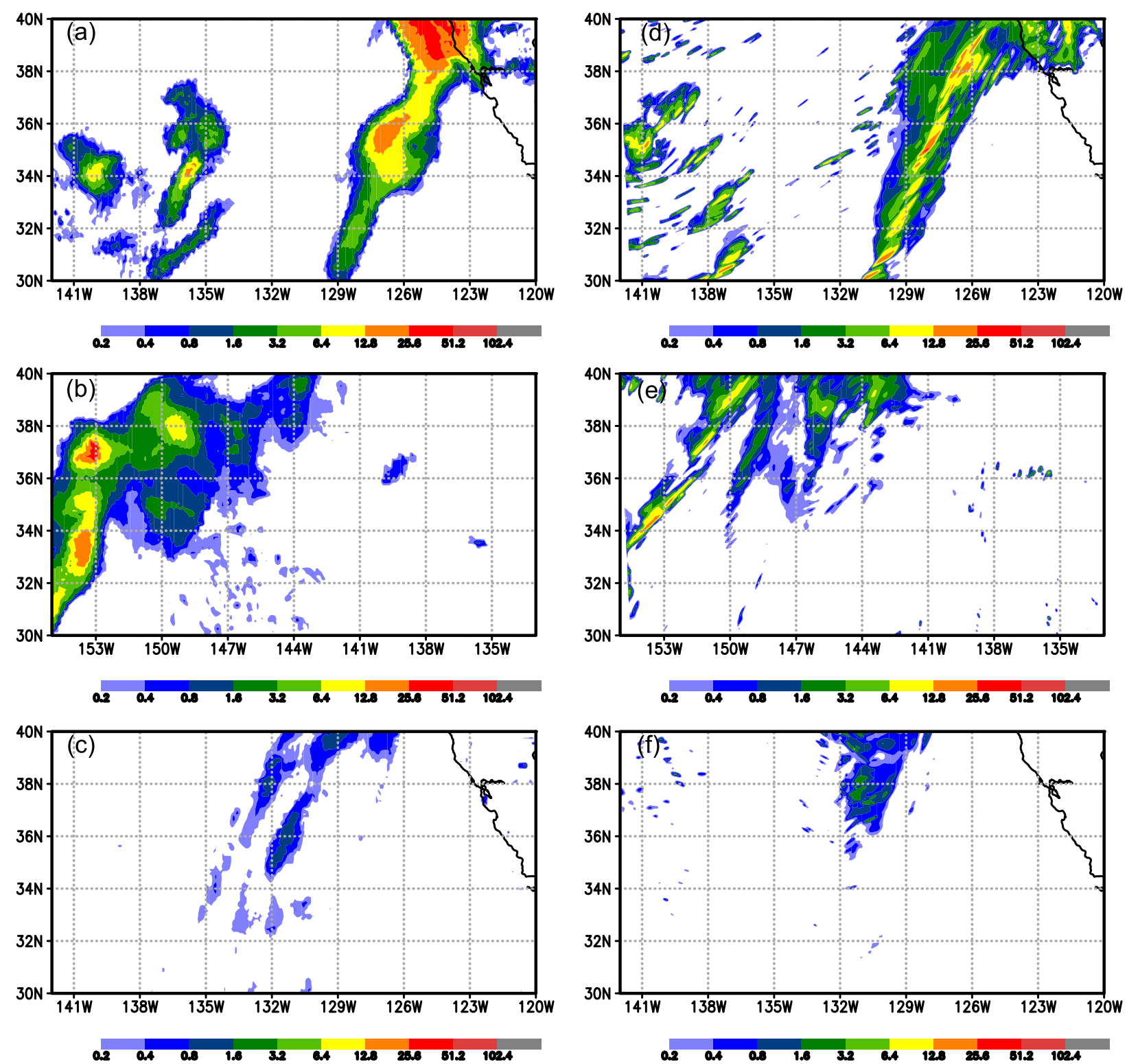

FIG. 3. Horizontal distributions of 1-h accumulated rainfall amounts for (a),(d) 1500-1600 UTC 6 Feb 2015, (b),(e) 1800-1900 UTC 19 Feb 2015, and (c),(f) 1200-1300 UTC 15 Mar 2015, derived from (left) the multisatellite precipitation estimate with gauge calibration in GPM IMERG, version 5B, and (right) the NU-WRF Model simulations.

gridded product is $0.25^{\circ} \times 0.25^{\circ}$. Therefore, the NUWRF-simulated precipitation properties (i.e., LH, precipitation rate and radar reflectivity characteristics) are regridded to $0.25^{\circ} \times 0.25^{\circ}$ for constructing the CSH's new LUTs.

\section{a. NU-WRF-simulated $L H$ and its relationship with surface precipitation rate and radar reflectivity}

Transitioning the $\mathrm{CSH}$ algorithm to include higher latitudes and winter season events for GPM requires the addition and development of new LUTs based on the simulation of such events, which are often shallower and have weaker convection as a result of the diminished instability at higher latitudes and in colder conditions. For example, Fig. 5 shows the convectivestratiform separation for one of the East Coast synoptic winter storm and one of the CalWater atmospheric river case; the convective-stratiform separation is based on the rainfall-type algorithm used for the TRMM Standard Product (TSP) 2A-54 (e.g., Wolff et al. 2005), whose program originated from Steiner et al. (1995), except that the rainfall classification in TSP 

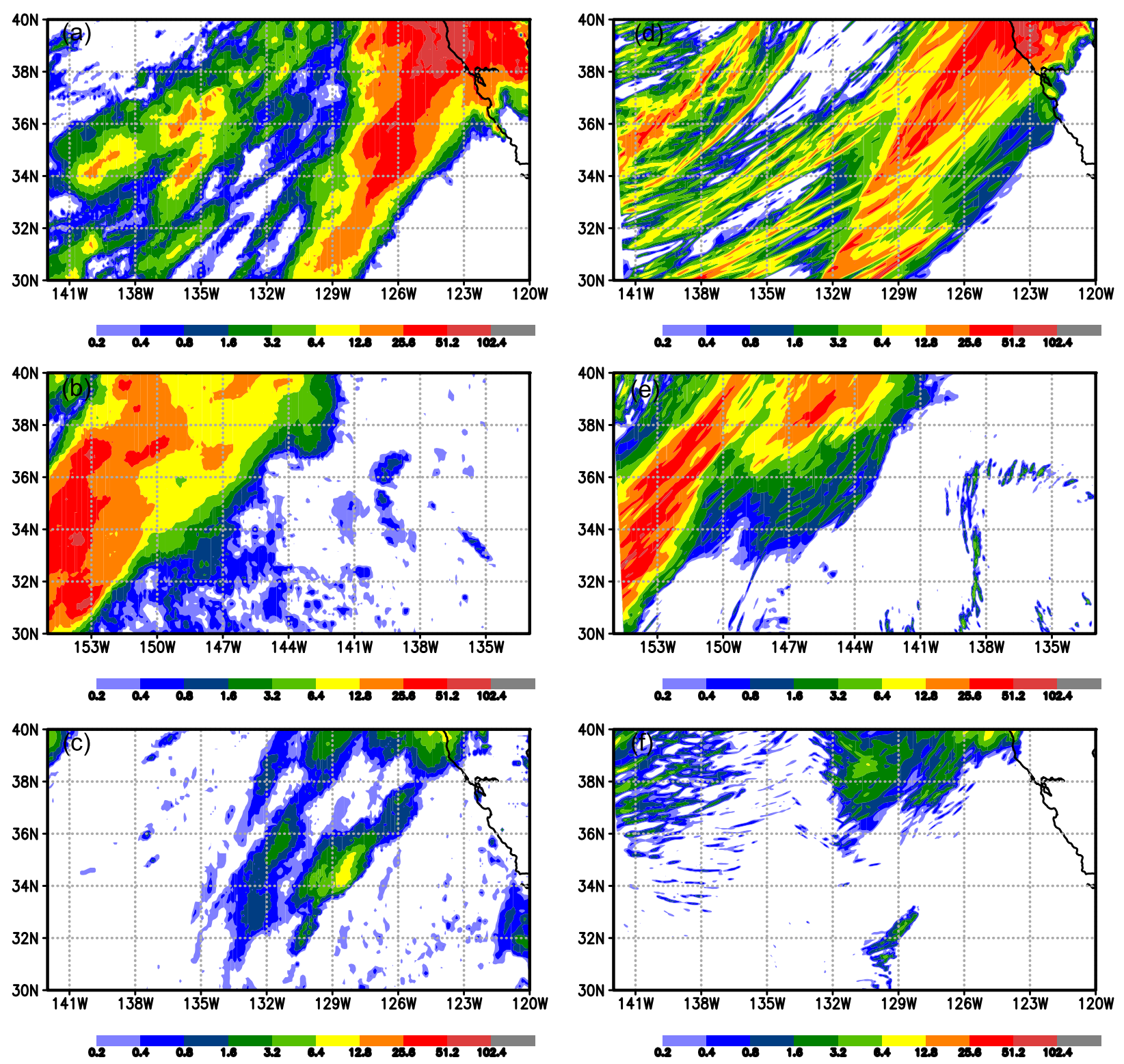

FIG. 4. Horizontal distributions of 12-h accumulated rainfall amounts (a),(d) from 1200 UTC 6 Feb to 0000 UTC 7 Feb 2015 , (b),(e) from 1200 UTC 19 Feb to 0000 UTC 20 Feb 2015, and (c),(f) from 1200 UTC 15 Mar to 0000 UTC 16 Mar 2015, derived from (left) the multisatellite precipitation estimates with gauge calibration in GPM IMERG, version 5B, and (right) the NU-WRF Model simulations.

2A-54 does not have a shallow (weak) rain category. It shows a broad stratiform classification covers almost the entire system for both cases. The convective classification mainly covers a very small area with relatively high surface precipitation rates. These convective-stratiform features are very different from those associated with tropical and midlatitude mesoscale convective systems. New metrics for selecting/assigning LUTs for high-latitude winter systems need to be explored.
The first step is to identify and quantify basic relations between GPM (TRMM) observable structures/quantities such as radar and precipitation and $\mathrm{LH}$ profiles simulated from NU-WRF. Officially, the CSH algorithm uses retrieved precipitation properties from the TRMM/ GPM combined algorithm as input. In addition to retrieved precipitation rates from the combined algorithm, corresponding information on echo-top heights, composite reflectivity (i.e., the maximum value in the column), maximum $\mathrm{dB} Z$ heights, vertical reflectivity 
(a) C-S separation 1800UTC Mar 16, 2014

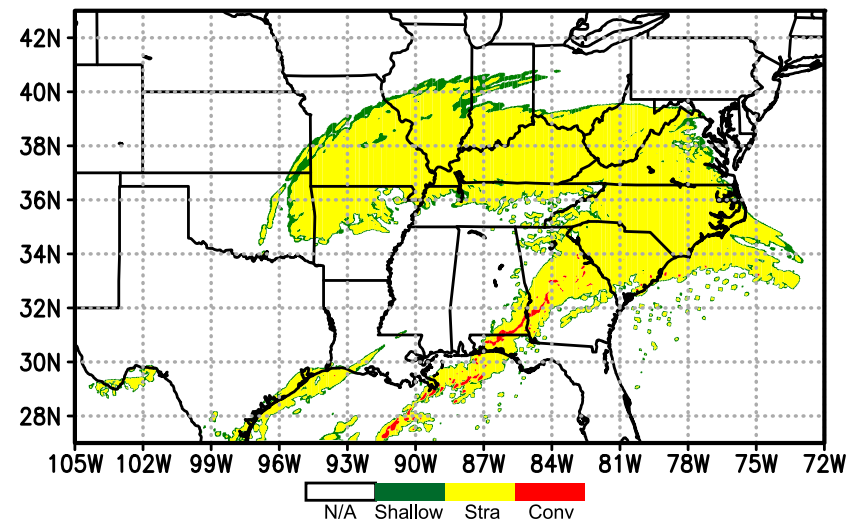

(b) C-S separation 1500UTC Feb 6, 2015

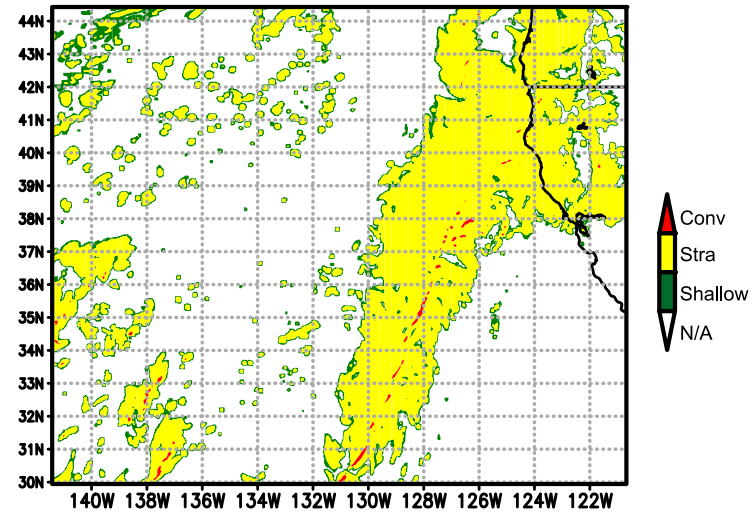

FIG. 5. Convective-stratiform classification based on a Steiner separation algorithm (a) at 1800 UTC for the 16 Mar 2014 East Coast winter storm case and (b) at 1500 UTC for the 6 Feb 2015 CalWater case.

gradients, and freezing-level heights is available from the $\mathrm{DPR}^{2}$ (and reanalysis data). For the new "extratropical" algorithm, LH LUTs based on these retrieved/observed properties will be derived from the NU-WRF simulations. The relationships between LH profiles, radar reflectivity (i.e., maximum column intensity and its height), freezing height, echo-top height, and surface precipitation (i.e., intensity) must be established. Figures $6 \mathrm{a}$ and $6 \mathrm{~b}$ show the composite radar reflectivity and surface precipitation rate for an East Coast winter event. There is a high correlation between precipitation rate and composite radar reflectivity. High (low) composite $\mathrm{dBZs}$ are always coincident with large (small) surface precipitation rates; composite radar reflectivity of $>40 \mathrm{dBZ}$ corresponds to precipitation rates of $>12 \mathrm{~mm} \mathrm{~h}^{-1}$. Also, the region with high precipitation rates has a high freezing level (Fig. 6c) as it mainly occurred in the southern part of the system. High precipitation rates are also usually associated with maximum radar echoes at a low height (Fig. 6d). This may indicate that warm rain processes dominate in the high precipitation rates.

A vertical cross section of radar reflectivity $(\mathrm{dB} Z)$ and LH rate $\left(\mathrm{K} \mathrm{h}^{-1}\right)$ through the high composite $\mathrm{dBZs}$ and surface precipitation rates (red line in Fig. 6a) are shown in Figs. $7 \mathrm{a}$ and $7 \mathrm{~b}$, respectively. The $0^{\circ}$ and $-40^{\circ} \mathrm{C}$ isotherms are also shown to indicate their relationship with $\mathrm{LH}$ and radar reflectivity. The results indicate that high $\mathrm{dBZs}(>42 \mathrm{dBZ})$ always occur beneath the freezing level for this case. Strong (weak) latent heat release and high (low) dBZs are located in the southern (northern) sector of the system. Strong cooling (evaporation + melting)

\footnotetext{
${ }^{2}$ In actual CSH GPM retrievals, these radar characteristics are obtained from the Ku-band normal scan.
}

is usually located beneath the freezing level. There is also substantial cooling above the freezing level due to sublimation located between the two regions of strong heating. Higher $\mathrm{dB} Z \mathrm{~s}$ beneath the freezing level are usually collocated with stronger LH aloft (above freezing level). $\mathrm{LH}$ is also simulated near to the $-40^{\circ} \mathrm{C}$ level.

Figures $7 \mathrm{c}$ and $7 \mathrm{~d}$ show the composite radar reflectivity and surface precipitation rate and the maximum LH and echo-top height, respectively. The black bold line shown in Fig. 7c denotes $13 \mathrm{dBZ}$ (approximately minimum detection for the DPR). Again, the higher the composite radar reflectivity is, so too is the surface precipitation rate (Fig. 7c). Also, the stronger the LH is, the higher echo-top height is (Fig. 7d). However, these two relationships are not always true. The composite radar reflectivity can be over $30 \mathrm{~dB} Z$ with a very low surface precipitation rate in the northern sector of the system. Echo-top heights can also be over 5-6 km but with a very small amount of LH in the northern sector of the system. LH is mainly in the form of cooling or weak heating beneath the freezing level $\left(0^{\circ} \mathrm{C}\right)$ in the northern sector of the system (Fig. 7b).

The relationship between LH and precipitation properties is also examined for the 6 February CalWater case. The results indicate that there is a clear relationship between composite radar reflectivity and surface precipitation rate as with the CONUS winter event (Figs. 8a,b). Higher composite radar reflectivity is always coincident with a larger surface precipitation rate for both CalWater and CONUS cases. High freezing levels with maximum radar reflectivities located at low levels characterize the southern and eastern sectors of the 6 February system (Figs. 8c,d). Freezing levels are lower, maximum radar reflectivity heights are higher, and surface precipitation rates are low in the northern and western sector of the 
(a) Composite radar reflectivity (dBZ)

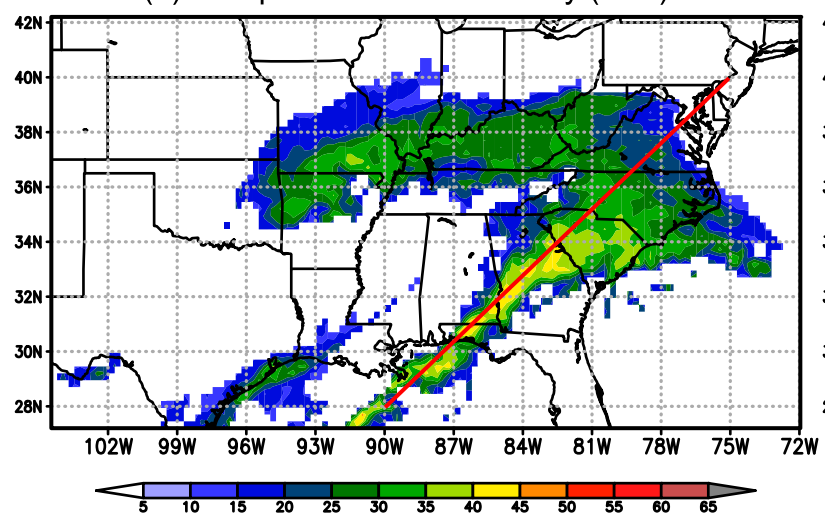

(b) Precipitation rate $(\mathrm{mm} / \mathrm{hr})$

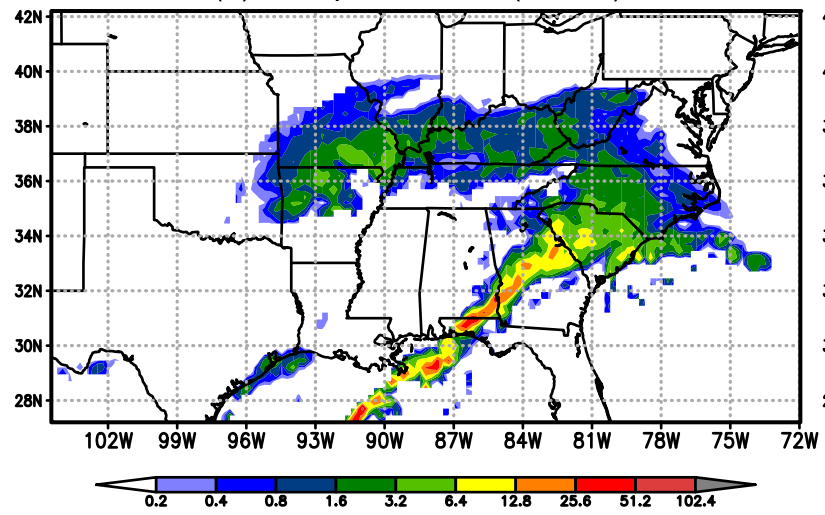

(c) Freezing level height $(\mathrm{m})$

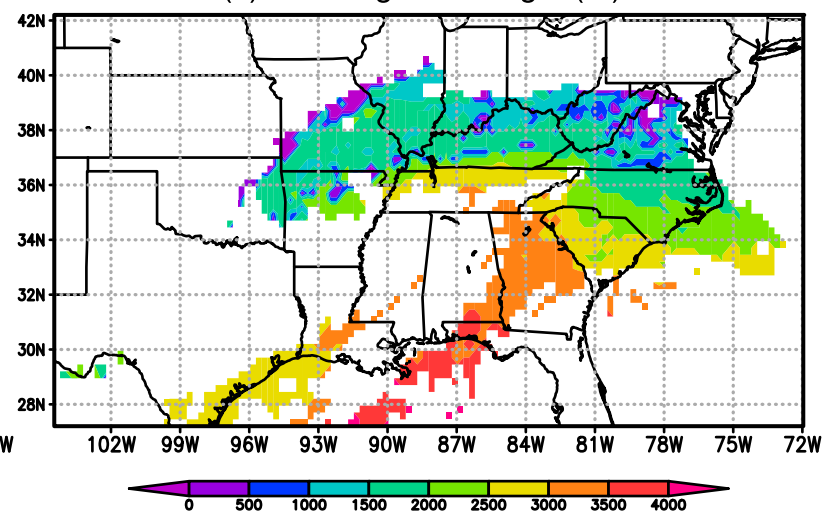

(d) Height of max radar signal intensity (m)

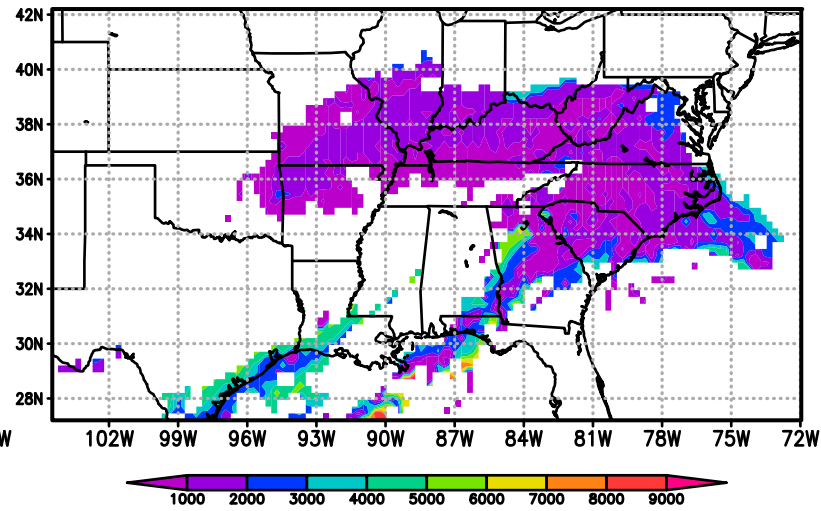

FIG. 6. Horizontal distributions of (a) composite radar reflectivity, (b) precipitation rate, (c) freezing-level height, and (d) height of maximum radar reflectivity at 1800 UTC 16 Mar 2014 derived from the NU-WRF simulation. The red line in (a) denotes the horizontal location of the distributions of maximum radar reflectivity and precipitation rate and the vertical cross section of radar reflectivity and $\mathrm{LH}$ in Fig. 7, below.

system. These features (or relationships) are very similar to the CONUS winter case.

Figure 9 shows the relationship between LH structure and radar reflectivity properties (i.e., echo-top height and maximum radar intensity) for the 6 February CalWater case. In general, the relationships between $\mathrm{LH}$, surface precipitation rate, radar reflectivity profiles, and echo-top heights are similar to those in the CONUS case (see Fig. 7). Strong LH is coincident with high radar reflectivity (Figs. 9a,b), and high precipitation rates are coincident with high maximum composite radar reflectivities. There are a few notable differences between this CalWater case and the CONUS winter case. For CalWater, peak radar reflectivity is lower down and weaker with smaller LH (Figs. 9a,b vs Figs. 7a,b); it also has lower surface precipitation rates with lower maximum radar intensity heights and weaker maximum LH with lower echo-top heights (Figs. 9c,d vs Figs. 7c,d). The main reason for the differences is that the CalWater case occurred over open ocean. Differentiating the NU-WRF-simulated LH against these precipitation properties for both oceanic and continental winter systems allows for more flexibility in building an algorithm LUT. ${ }^{3}$

\section{b. New classifications}

The results suggest that all of the aforementioned NU-WRF-simulated precipitation quantities should be used to build relationships with LH. Collectively, LH estimates can be made and refined according to the ambient reflectivity/precipitation structures and thus provide the basis by which the CSH algorithm and its LUTs can be expanded to colder environments. Table 6 shows the key parameters, that is, surface precipitation rate $\left(\mathrm{mm} \mathrm{h}^{-1}\right)$, composite radar reflectivity height (meters),

\footnotetext{
${ }^{3}$ Although both the CSH tropical and extratropical LUTs are composited into land and ocean categories, currently no other surface characteristics are considered such as ice cover. Also, areas with terrain in excess of $500 \mathrm{~m}$ are excluded from the extratropical LUTs; terrain is not included in the tropical LUTs.
} 
a) NU-WRF radar reflectivity (dBZ)

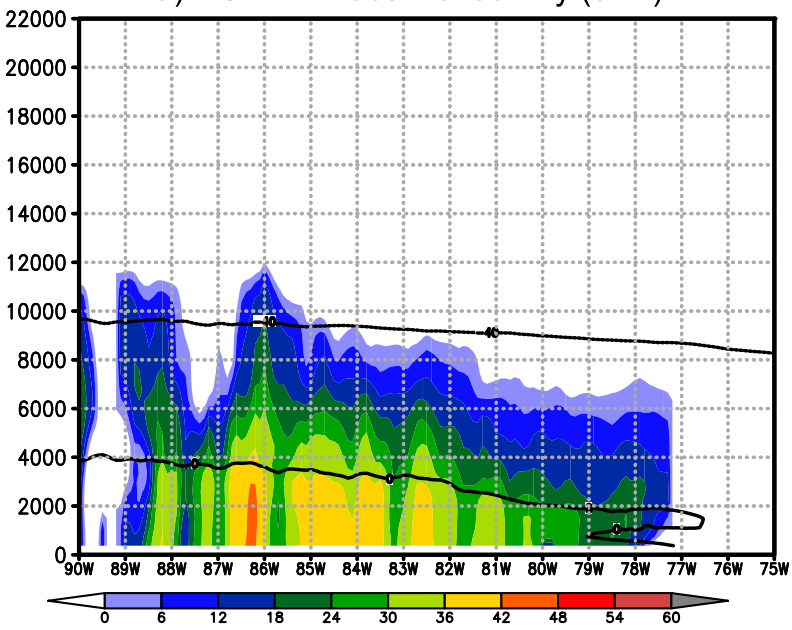

b) NU-WRF simulated original LH (K/hr)

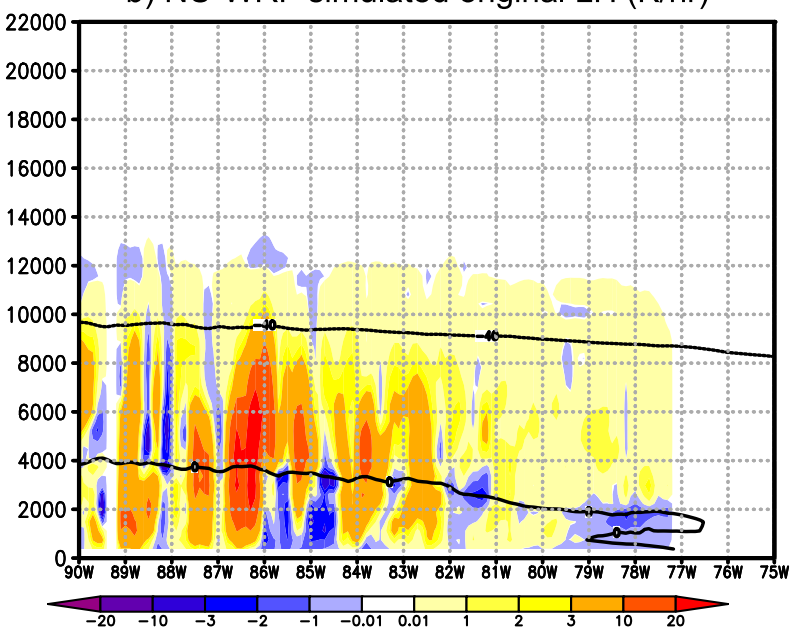

c) Max dBZ \& Rainfall on the cross section —Rainfall rate (mm/hr) —Composite Reflectivity (dBZ)

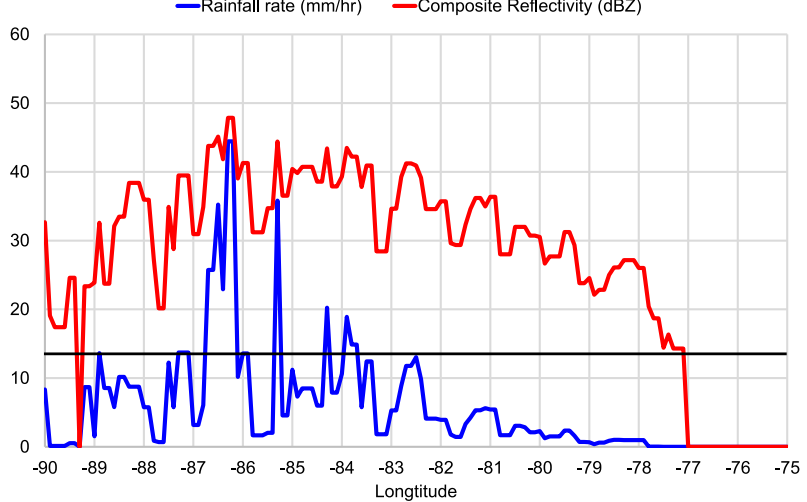

d) Max LH \& Echo-top height on the cross section

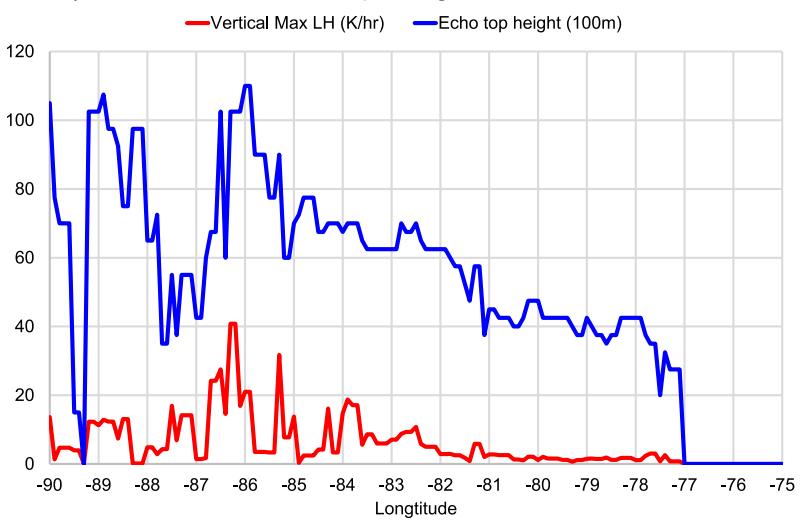

FIG. 7. Vertical cross section showing (a) radar reflectivity $(\mathrm{dBZ})$ and (b) latent heating rate $\left(\mathrm{K} \mathrm{h}^{-1}\right)$. Also shown are the corresponding (c) composite radar reflectivity and precipitation rate and (d) maximum latent heating rate and radar echo-top height along the cross section (red line) in Fig. 6 at 1800 UTC 16 Mar 2014. Note that the horizontal thick black line in (c) denotes $13 \mathrm{dBZ}$.

freezing-level height (meters), echo-top height (meters), decreasing flag, ${ }^{4}$ and composite radar reflectivity intensity ( $\mathrm{dBZ}$ ), which are to be used for the new CSH coldseason LH LUT. The bin ranges are based on the close examination of the results from the NU-WRF-simulations as shown in the previous figures (i.e., Figs. 6-9). Also note that the range of the surface precipitation intensity and other precipitation properties (radar reflectivity, freezing-level height) are selected through detailed analysis of the NU-WRF simulations. Over $10000 \mathrm{LH}$ profiles in total are generated.

\footnotetext{
${ }^{4}$ Starting from the height of the maximum $\mathrm{dB} Z$ value, if the reflectivity values drop by more than $10 \mathrm{~dB} Z$ toward the surface, then the column is flagged as "decreasing"; otherwise it is "nondecreasing."
}

Examples of the LH structures in the LUT from the NU-WRF simulations are shown in Fig. 10. Note that these LH structures and their associated precipitation properties are regridded to $0.25^{\circ} \times 0.25^{\circ}$. Consequently, the surface precipitation intensity (or rate) is weaker than those shown in Figs. 2 and 3. Figures 10a-c are for relatively strong surface precipitation intensity (from $10-17,17-31 \mathrm{~mm} \mathrm{~h}^{-1}$ ) with different echo-top heights (4000-5000 and 7000-8000 m), and different freezing heights (2500-3000, 3500-4000, and 4500-5000 m) and maximum dBZ heights (0-500, 500-1000, and 1000$1500 \mathrm{~m})$. Stronger surface precipitation rate, higher echo height, and higher reflectivity are associated with stronger and deeper LH (Figs. 10b,c) as compared with weaker surface precipitation rate, lower echo-top height, 
(a) Composite radar reflectivity (dBZ)

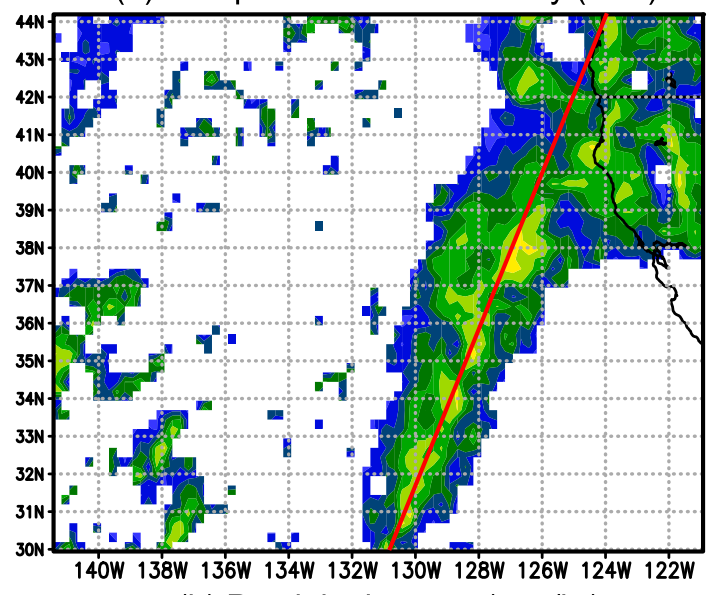

(b) Precipitation rate $(\mathrm{mm} / \mathrm{hr})$

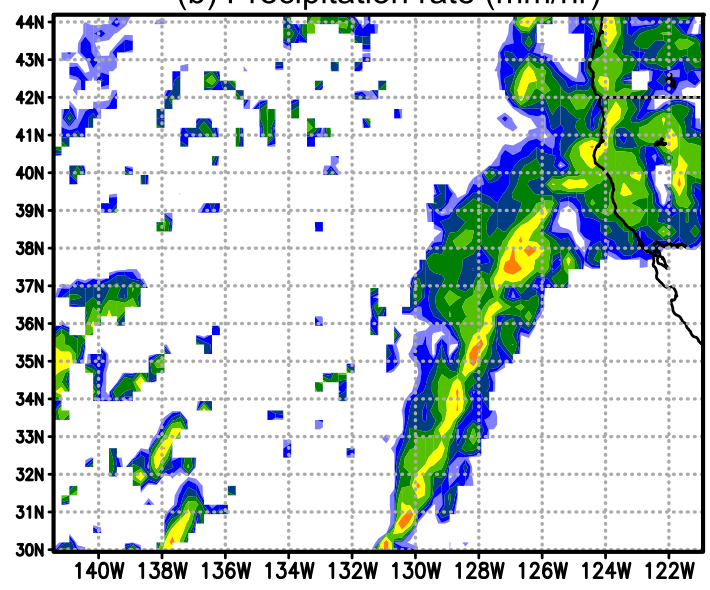

(c) Freezing level height $(\mathrm{m})$
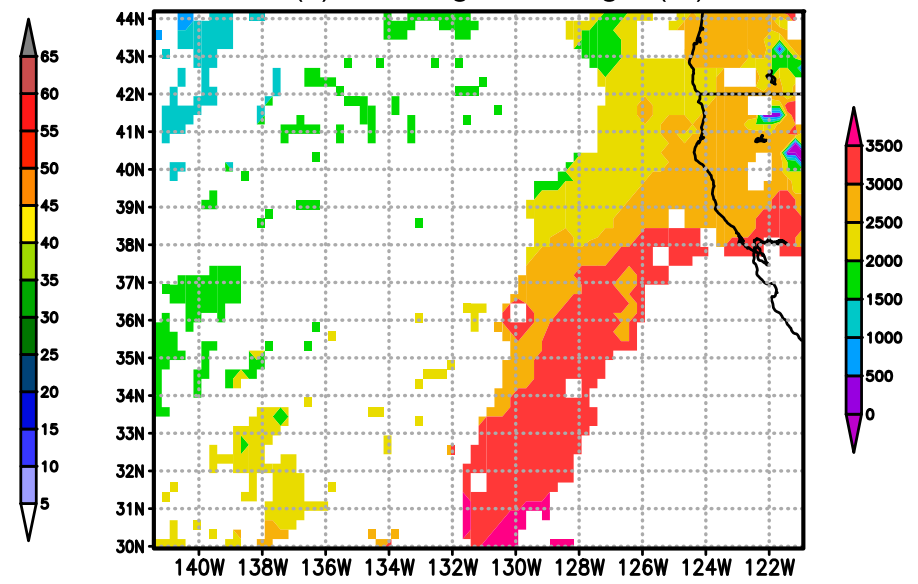

(d) Height of max radar signal intensity $(m)$

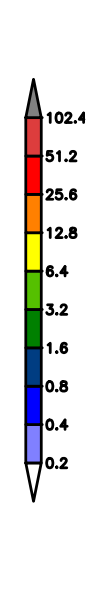

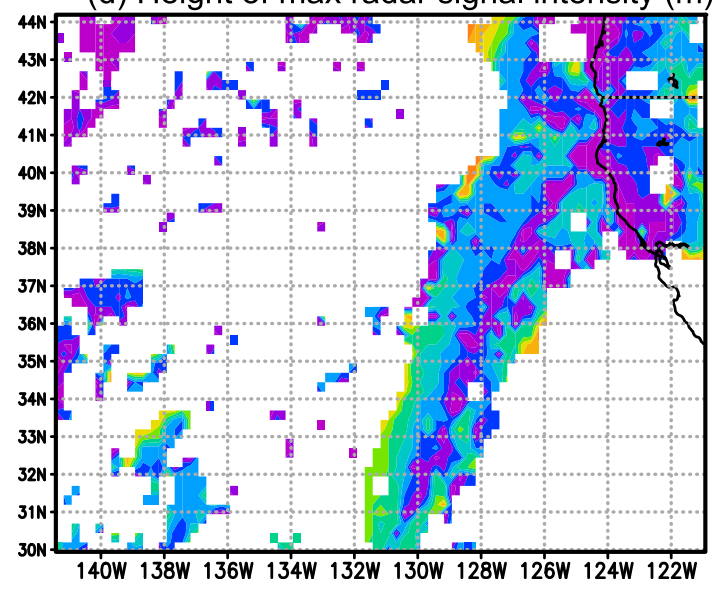

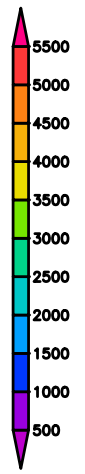

FIG. 8. As in Fig. 6, but for the 6 Feb 2015 CalWater case at 1500 UTC.

and lower freezing level (Fig. 10a). Interestingly, these three LH structures are characteristic of convective LH profiles for organized convective systems with heating extending from the lower to upper troposphere.

Figures $10 \mathrm{~d}-\mathrm{f}$ show the $\mathrm{LH}$ profiles associated with weak surface precipitation rates $\left(0-1 \mathrm{~mm} \mathrm{~h}^{-1}\right)$, higher maximum radar reflectivity height (2000-4000 m) and a higher freezing level relative to those shown in Figs. 10a-c. These LH structures all show cooling beneath the freezing level and heating aloft and are quite similar to those in the stratiform region of organized (mesoscale) convective systems. The strength of the lowlevel cooling is very different in these three LH structures. Weaker surface precipitation rates (Figs. 10d,f) have stronger low-level cooling versus the low rainfall rates in Fig. 10e. There is stronger cooling near the freezing level for those shown in Figs. 10e and 10f due to the higher echo-top heights. The cooling profile is uncorrelated with reflectivity intensity as shown in Fig. 10e. The heating aloft is also different in these LH structures.
A higher freezing level, higher echo-top height, and higher maximum reflectivity height have stronger $\mathrm{LH}$ aloft (Figs. 10e,f) versus a lower freezing level, lower echo-top height, and lower maximum reflectivity height (Fig. 10d).

In addition, some LH profiles in the LUT correspond to midlevel clouds (Figs. 10g,h). These NU-WRF-simulated LH profiles have moderate rainfall rates, $3-10 \mathrm{~mm} \mathrm{~h}^{-1}$, echo-top heights, $3000-4000 \mathrm{~m}$, and freezing-level height, $3000-3500 \mathrm{~m}$. The only difference between these two LH profiles is the maximum reflectivity height. The one with a higher maximum reflectivity height has strong low-level LH for radar intensities of 25-35 dBZ (Fig. 10h).

There are LH profiles in the LUT characteristic of shallow clouds. Figures $10 \mathrm{i}$ and $10 \mathrm{j}$ are two examples of LH profiles for low echo-top heights (below $2 \mathrm{~km}$ ). One LH profile (Fig. 10i) has 1000-2000 $\mathrm{m}$ echo tops and $1-3 \mathrm{~mm} \mathrm{~h}^{-1}$ precipitation rates and shows strong LH $\left(\sim 10 \mathrm{~K} \mathrm{~h}^{-1}\right)$ for radar intensities of $25-30 \mathrm{dBZ}$ (Fig. 10i). The other has small precipitation rates $\left(0-1 \mathrm{~mm} \mathrm{~h}^{-1}\right)$ and very low echo-top heights $(0-1000 \mathrm{~m})$ and has mainly 
a) NU-WRF radar reflectivity (dBZ)

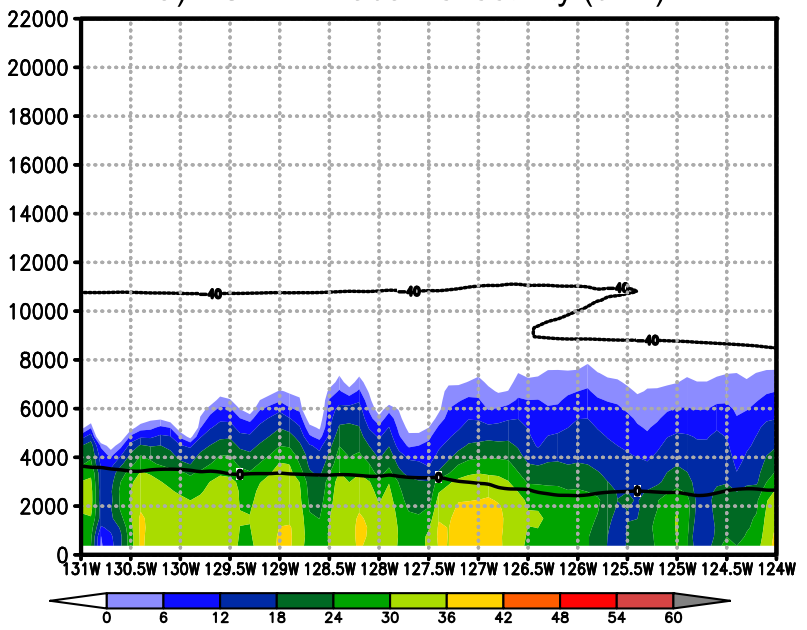

b) NU-WRF simulated original $\mathrm{LH}(\mathrm{K} / \mathrm{hr})$

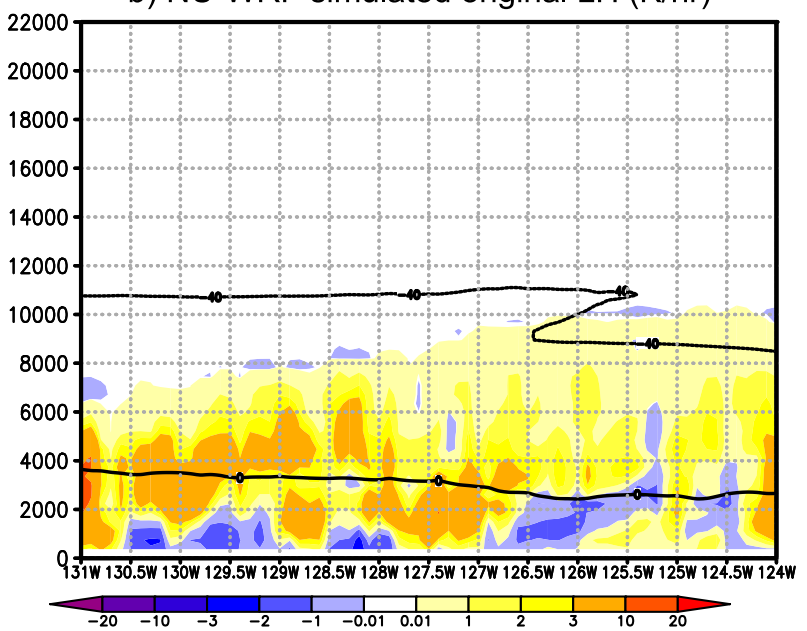

c) Max dBZ \& Rainfall on the cross section

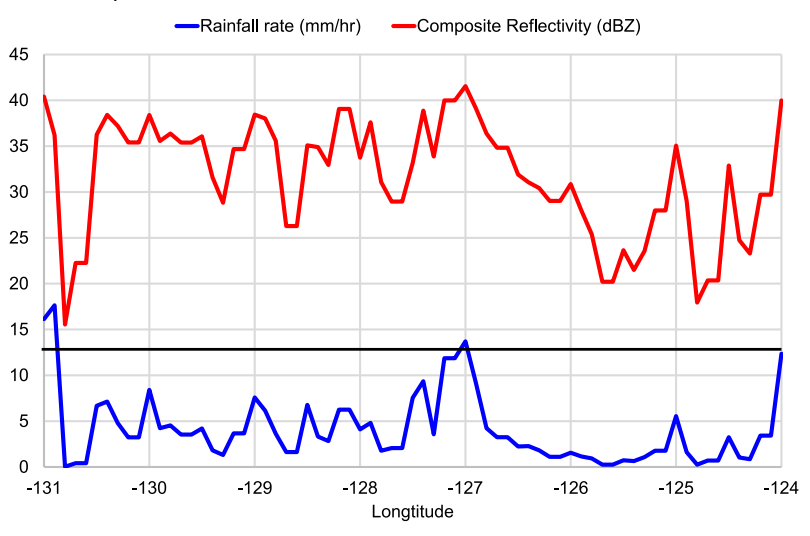

d) Max LH \& Echo-top height on the cross section

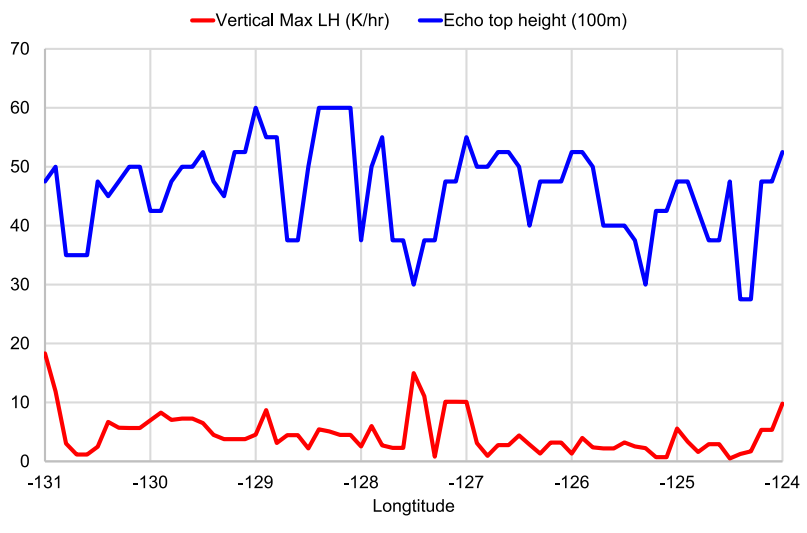

FIG. 9. As in Fig. 7, but for the 6 Feb 2015 CalWater case at 1500 UTC.

weak LH (less than $3 \mathrm{Kh}^{-1}$ ) around $20 \mathrm{dBZ}$ (Fig. 10j). Both LH profiles have very weak cooling from 2 to $5 \mathrm{~km}$ and very weak heating above $5 \mathrm{~km}$.

\section{Consistency check}

As with the development of the $\mathrm{CSH}$ algorithm, the first form of validation with the revised algorithm is via self-consistency checks (see Tao et al. 2000, 2006, 2010) wherein LUTs derived from one or more simulated synoptic events can be used with the new algorithm to retrieve heating for an independent synoptic event with the modeled LH fields for that event serving as truth. In this way, an optimal set of conditions, relations and LUTs can be identified based on biases and errors obtained via the self-consistency checks using the model as truth.
Figure 11 shows a schematic diagram on how to use the NU-WRF-simulated precipitation and radar reflectivity to produce the LUT. The NU-WRF-simulated original LH profile is the truth. On the other hand, NUWRF-simulated LH profiles are retrieved from the LUT based on the rainfall rate, maximum $\mathrm{dB} Z$ height, echotop height, and freezing-level height as discussed in the previous section. Figure 11 also shows how to perform the self-consistency check. The NU-WRF-simulated precipitation and its related properties (for actual retrievals the GPM combined algorithm precipitation properties are used) serve as the input for LH retrieval. A specific LH profile is selected from the new LH LUT based on the specific precipitation rate and other precipitation properties. It is then compared with the actual NU-WRFsimulated LH profile, which serves as the truth in this self-consistency check. 
TABLE 6. Key parameters used for the new CSH cold-season LH LUT. The LUT is built from NU-WRF-simulated LH profiles associated with six synoptic storm events.

\begin{tabular}{lc}
\hline \hline \multicolumn{1}{c}{ Variables } & Bin ranges \\
\hline Surface rainfall & $0.0,0.178,1.0,1.78,3.16,5.62,7.5,10.0$, \\
rate $\left(\mathrm{mm} \mathrm{h}^{-1}\right)$ & $13.3,17.8,22.4,27.0,31.6,44.0,56.2$, \\
& $70.0,100.0$, and 999.0 \\
Max dBZ height (m) & $0.0,500.0,1000.0,1500.0,2000.0,3000.0$, \\
& $4000.0,5000.0$, and 99 999.0 \\
Freezing-level & Negative, $0.0,500.0,1000.0,1500.0,2000.0$, \\
height $(\mathrm{m})$ & $2500.0,3000.0,3500.0,4000.0,4500.0$, \\
& $5000.0,5500.0$, and 99999.0 \\
Echo-top height $(\mathrm{m})$ & $0.0,1000.0,2000.0,3000.0,4000.0,5000.0$, \\
& $6000.0,7000.0,8000.0,9000.0,10000 .$, \\
& and 99999.0 \\
Decreasing flag & Decreasing or nondecreasing \\
Max dBZ intensity & $-10,-9,-8, \ldots, 78,79$, and 80 (from \\
& -10 to 80, with an interval of 1$)$ \\
\hline
\end{tabular}

Self-consistency checks for two different sets of LUTs are conducted. The first set of LUTs is produced from the NU-WRF simulations at a specific time (i.e., 1800 UTC 16 March 2014 for the CONUS case). The second set is produced from 24 -h NU-WRF simulations with 10-min output intervals for the CONUS 16 March 2014 case (except for the first $6 \mathrm{~h}$ ). LH profiles from the two sets of LUTs are then compared against the NU-WRF-simulated original LH profiles at the specific time as truth.

Figure 12 shows the horizontal distribution of the NUWRF-simulated (original) and retrieved maximum (heating) and minimum (cooling) LH at 1800 UTC 16 March 2014 for the CONUS case. Large (maximum) heating is mainly simulated along the southern part of the system (Fig. 12a). It is almost collocated with the maximum precipitation rates (Fig. 6b) as well as the maximum composite radar reflectivities (Fig. 6a). Large cooling also occurs in the southern sector of the system, and it is located on the west side of the maximum LH. The retrieved LH from the first type of LUT (concurrent in time; Figs. 12b,e) is in excellent agreement with the NU-WRF-simulated LH. The only difference is that the retrieved LH does not show any heating or cooling in Maryland and northwestern Virginia. Overall, the retrieved LH from the second type of LUT (cumulative) is also in good agreement with NU-WRF-simulated LH (Figs. 12c,f). However, both the retrieved maximum heating and minimum cooling are weaker than the NUWRF-simulated ones as well as the retrieved ones from the first type of LUT. However, they have better areal coverage (Maryland and northwestern Virginia) than the retrievals from the first type.

To examine the performance of the algorithm further, vertical cross sections of the NU-WRF-simulated (original) and retrieved LH structures parallel to the maximum LH (see the line shown in Fig. 12a) and in the east-west direction in the northern part of system (see the line shown in Fig. 12b) are constructed in Fig. 13. LH (heating) occurs from low to upper levels (up to $10 \mathrm{~km}$ ) in the southern sector of the system, while low-level cooling is present in the northern sector of the system (Fig. 13a). For the eastwest cross section, low-level cooling dominates with weak heating mainly above the freezing level (Fig. 13d). The retrieved LH structures from the first type of LUT are in excellent agreement with NU-WRF-simulated LH for these two cross sections (Figs. 13b,e). The main differences between the simulated and retrieved $\mathrm{LH}$ are heating and cooling at the end of the southern sector of the system. The retrieved LH profiles do not have any heating (Fig. 13b). In addition, the retrieved heating aloft is weaker in the eastwest cross section than the NU-WRF-simulated heating (Fig. 13d). As shown in Fig. 12, retrieved heating and cooling are also missing over Maryland and the northwest part of Virginia. For the second self-consistency check, the retrieved LH structures along (parallel to) the maximum heating agree with the NU-WRF-simulated LH (Fig. 13c), but the retrieved heating and cooling structures are very weak relative to the NU-WRF-simulated ones in the westeast cross section (Fig. 13f).

A self-consistency check is also conducted for the 6 February CalWater case. Figure 14 shows horizontal distributions of the NU-WRF-simulated and retrieved maximum (heating) and minimum (cooling) LH for this case. This case is located off of the West Coast and organized in a linear structure (Figs. 3 and 8). Strong heating (Fig. 14a) also occurs in a linear structure and is collocated with the high surface precipitation rates (Fig. 8b) and high composite radar reflectivities (Fig. 8a), while strong cooling (Fig. 14d) occurs on the western side of the strong heating near the western edge of the system. It is also collocated with higher radar echo tops (Fig. 8d). The retrieved maximum and minimum $\mathrm{LH}$ for the first self-consistency check (Figs. 14b,d) are again in an excellent agreement with the NU-WRF-simulated original LH. For the second self-consistency check, the retrieved strong heating and cooling are weaker than the NU-WRF-simulated ones (Figs. 14c,d). However, the areal coverage over land of retrieved maximum (heating) and minimum (cooling) is better than for the first selfconsistency check.

The vertical distribution of LH from NU-WRF and retrieved for this CalWater case are shown in Fig. 15. Two cross sections, the first parallel to the strong heating and the second parallel to the strong cooling (see lines in Figs. 14a and 14d, respectively), are shown as part of the self-consistency check. For the cross section with large heating, the strong heating occurs mainly in the southern 
a) 20150205_calwater

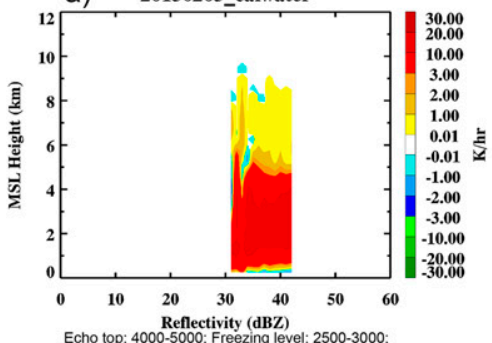

Max dBZ height: $1000-1500 ;$ Rain: $10-17$
Ma

b) 20140316 ne_winterstorm

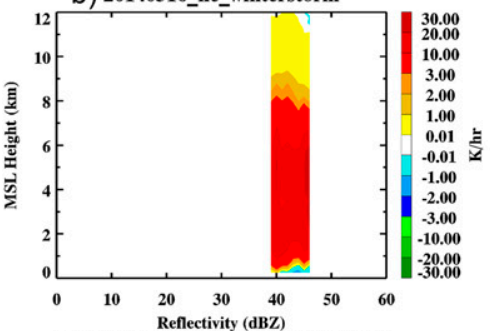

Echo top: $7000-8000 ;$ Freezing level: $3500-4000$
Max dBZ height: $500-1000 ;$ Rain: $17-31$

C) 20140316_ne_winterstorm

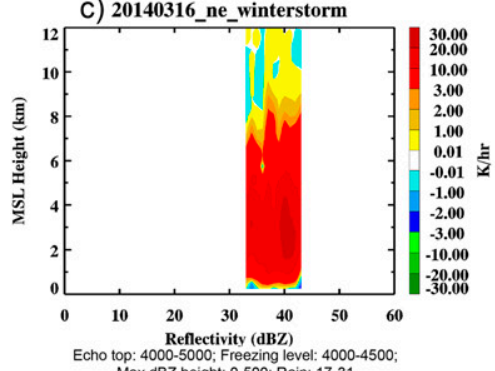

Max dBZ height: 0-500; Rain: 17-31

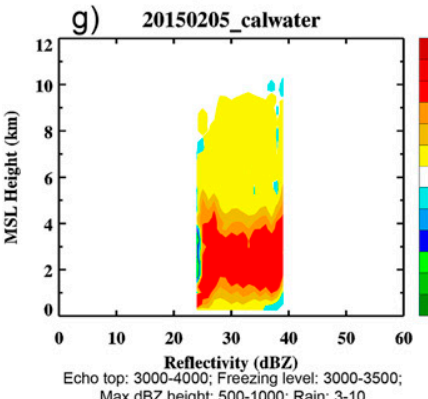

h) 20150205_calwater

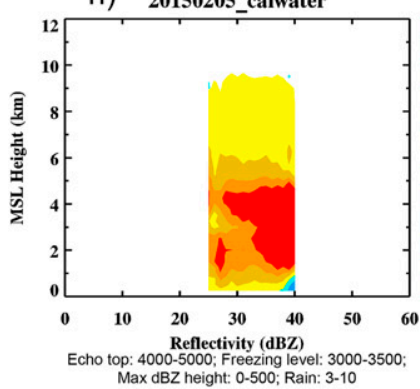

d) 20150205_calwater

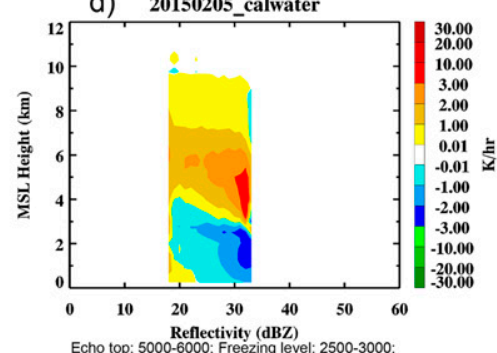

cho top: 5000-6000; Freezing level: 2500-3000;
Max dBZ height: 2000-3000; Rain: 0-1

e) 20150205_calwater

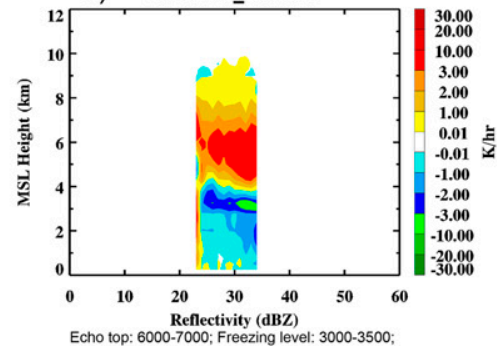

Echo top: 6000-7000; Freezing level: 3000-3500;
Max dBZ height: 3000-4000; Rain: 1-3

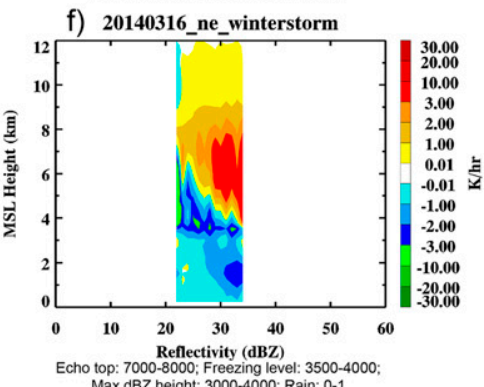

Max $7000-8000$; Freezing level: $3500-4000$;

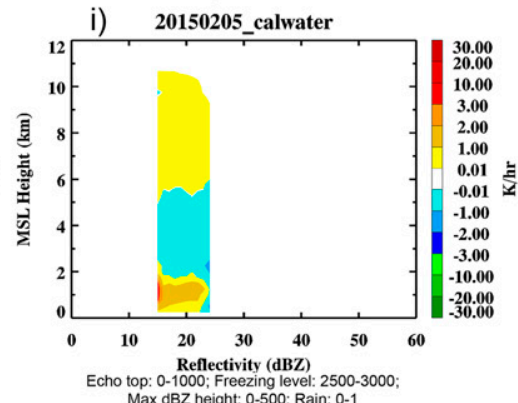

j) 20150205_calwater

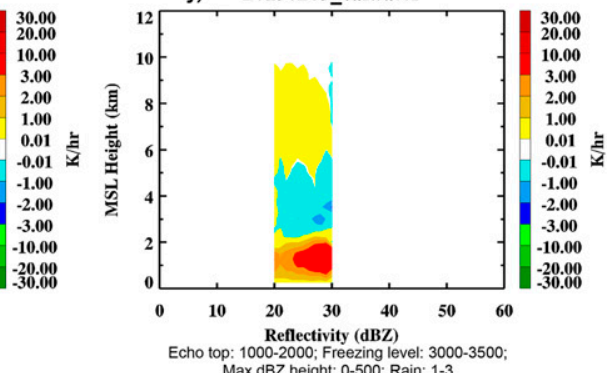

FIG. 10. Examples of latent heating profiles in the new cold-season LUT. See the text for more details on the characteristics (range of rain rates, freezing-level heights, echotop heights, and maximum radar reflectivity heights) of these latent heating profiles. MSL refers to height above mean sea level. 


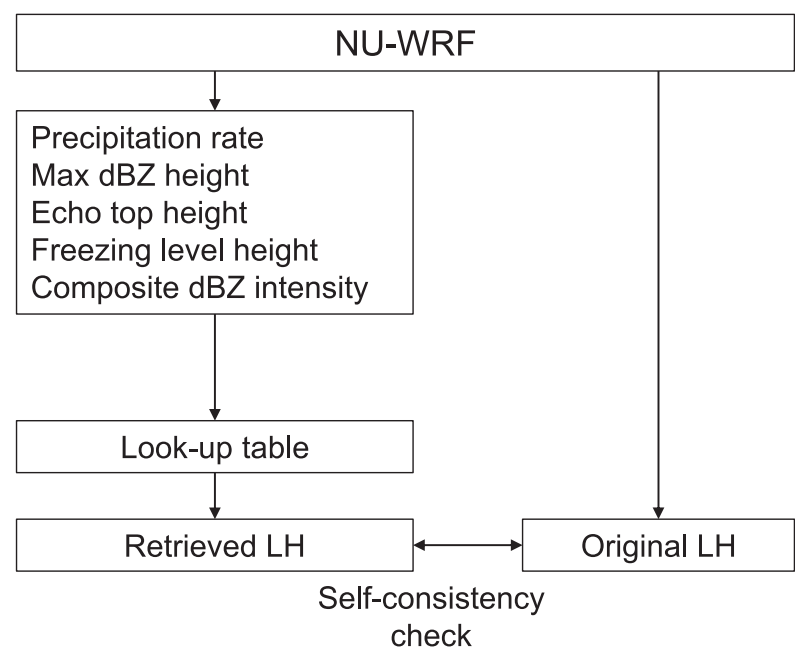

FIG. 11. Schematic diagram showing the new cold-season LUT production from the NU-WRF simulations and the consistency check.

part of the system with more cooling to the north (Fig. 15a). Cooling dominates below the melting level with weak heating above the melting level for the cross section with large cooling (Fig. 15d). The retrieved LH from the first self-consistency check is in excellent agreement with the NU-WRF-simulated LH (Figs. 15b,e). The retrieved cooling from the second self-consistency check is weaker than the NU-WRF-simulated cooling (Figs. 15c,f), but overall, the retrieved LH structures are in good agreement with the NU-WRF-simulated ones for the second self-consistency check.

There are differences in the LH structures between the CalWater and CONUS cases (Figs. 13 and 15). For example, the heating is weaker and shallower and less cellular in the CalWater case compared to the CONUS (Figs. 15a and 13a). On the other hand, cooling is stronger in the CalWater case compared to the CONUS (Figs. 15d and 13d). Cooling dominates and is very large in the lower troposphere and beneath the freezing level (Fig. 15d). These differences are shown clearly in the mean (cross section) profiles (Fig. 16). The level of mean maximum heating is around 5 (4) $\mathrm{km}$ in the CONUS (CalWater) case (Figs. 16a,d). The maximum heating is about $3.7 \mathrm{~K} \mathrm{~h}^{-1}$ in the CONUS case as compared with $2.5 \mathrm{~K} \mathrm{~h}^{-1}$ in the CalWater case. The maximum cooling is stronger $\left(\sim 1.4 \mathrm{~K} \mathrm{~h}^{-1}\right)$ in the CalWater case compared to $0.3 \mathrm{~K} \mathrm{~h}^{-1}$ in the CONUS case (Figs. 16e,b).

Figure 16 also shows the retrieved LH from both the first and second self-consistency checks. The retrieved mean vertical LH from the first self-consistency check is in excellent agreement with the NU-WRF-simulated $\mathrm{LH}$ for both the CONUS and CalWater cases. The LH profiles retrieved from the second self-consistency check have similar vertical distributions (i.e., level of maximum heating) to the NU-WRF-simulated profiles. For the CONUS case, there is a difference in heating between the second self-consistency check and those from the NU-WRF simulation and first self-consistency check (Fig. 16a). For example, differences $\left(\sim 0.2-0.3 \mathrm{~K} \mathrm{~h}^{-1}\right)$ occur mainly at low levels $(\sim 2-4 \mathrm{~km})$ for the east-west cross sections (Fig. 16b). On the other hand, the differences are slightly large $\left(\sim 0.5 \mathrm{~K} \mathrm{~h}^{-1}\right)$ for the cross section through the strong surface precipitation rates (Fig. 16a). For the CalWater case, the retrieved LH from the second self-consistency check is notably stronger $\left(\sim 0.5-0.6 \mathrm{~K} \mathrm{~h}^{-1}\right)$ than the NU-WRF-simulated $\mathrm{LH}$ and that from the first self-consistency check (Fig. 16d). There are also differences in cooling (but not heating; Fig. 16e) between the second selfconsistency check and the NU-WRF simulations and first self-consistency check in the western sector of the system (weaker surface rates).

The abovementioned self-consistency checks are tested for specific vertical cross sections. So, in addition, the same self-consistency checks are also applied over the whole NU-WRF simulation domains (Figs. $16 \mathrm{c}, \mathrm{f}$ ). The differences in heating and cooling between the first and second self-consistency checks are quite small for both the CONUS and CalWater cases, and both are in very good agreement with the NU-WRF-simulated LH. These results suggest that $\mathrm{LH}$ retrievals from the $\mathrm{CSH}$ algorithm on a localized time and spatial scale have much more uncertainty than when averaged over a larger scale. Specifically, while the basic vertical structure appears to be resolved on the scale of the cross sections, the magnitudes of the peaks in heating and cooling can have notable uncertainties, whereas on a larger scale (i.e., the NU-WRF domains used here) in addition to the vertical structure, the magnitude of heating/cooling appears much more resolved.

One additional self-consistency check is conducted. It is the same as the second self-consistency check but excludes the LH data from the first self-consistency check (i.e., the concurrent analysis time). In terms of horizontal distributions of maximum latent heating/ cooling rates and vertical cross sections of latent heating/cooling rates, the results between this and the second self-consistency check are very similar. Differences in the vertical profiles of horizontally averaged rates between the additional and second self-consistency check are also very small. The differences in heating and cooling over the whole NU-WRF simulation domains between the second and additional self-consistency checks are also quite small for both the CONUS and CalWater cases. The close agreement in these two 
(a) NU-WRF simulated original max LH (K/hr)

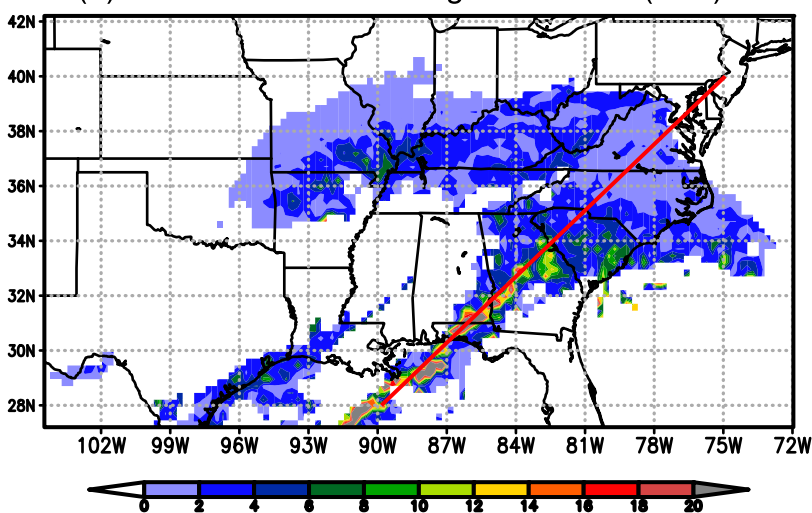

(b) Max LH (K/hr) retrieved using LUT from this time only

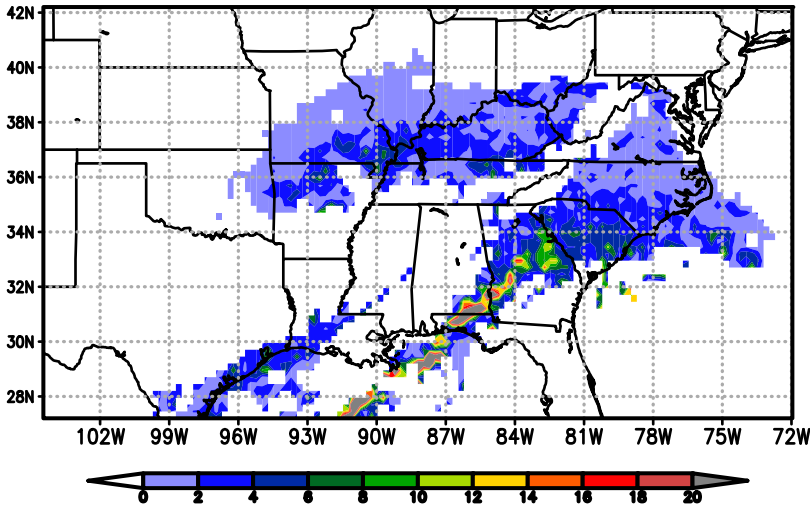

(c) Max LH (K/hr) retrieved using LUT from the whole time

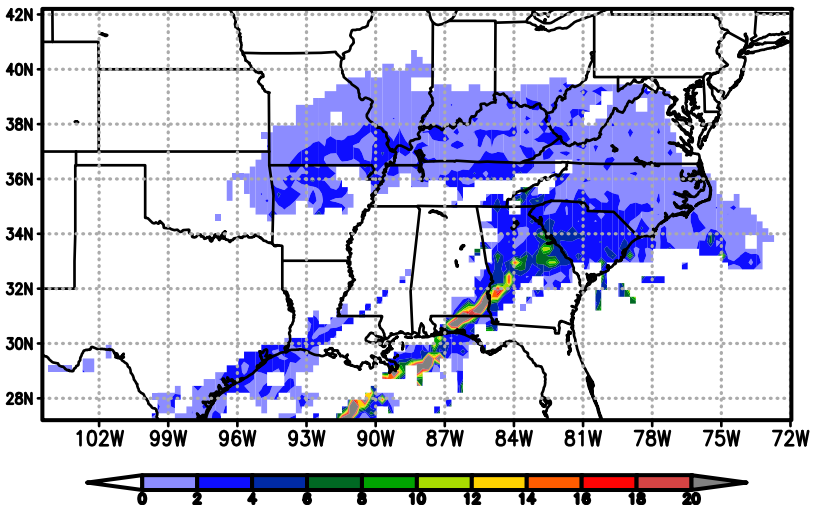

(d) NU-WRF simulated original min $\mathrm{LH}(\mathrm{K} / \mathrm{hr})$

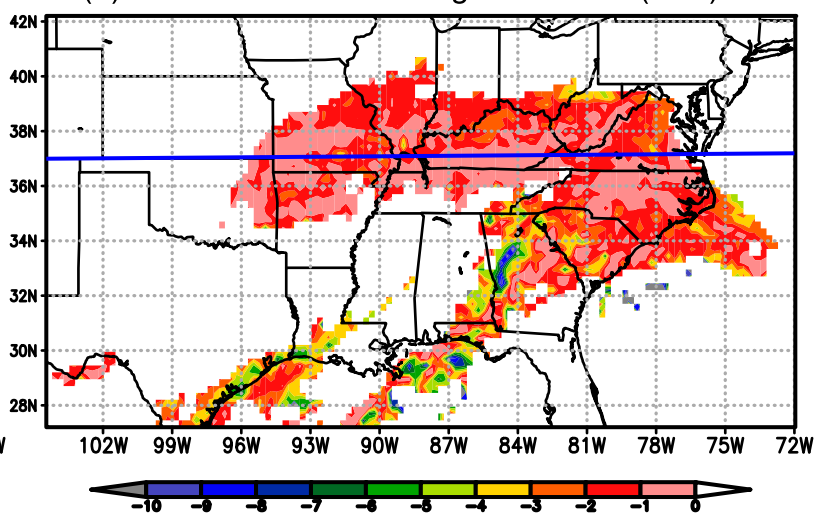

(e) Min LH (K/hr) retrieved using LUT from this time only

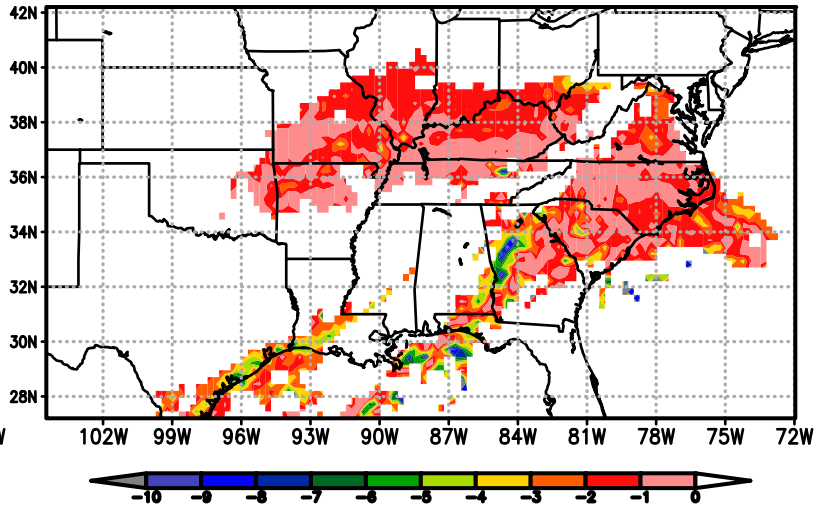

(f) Min LH (K/hr) retrieved using LUT from the whole time

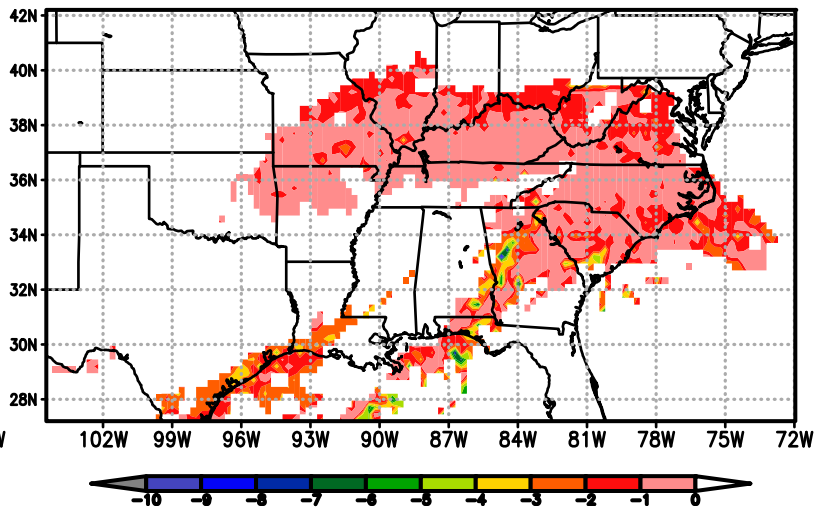

FIG. 12. Horizontal distributions of maximum latent heating rate $\left(\mathrm{K} \mathrm{h}^{-1}\right)$ at 1800 UTC 16 Mar 2014 (a) directly from the NU-WRF simulation, (b) retrieved using an LUT based on the NU-WRF simulation results at this specific time only, and (c) retrieved using an LUT based on the NU-WRF simulation results from every $10 \mathrm{~min}$ for the whole 24-h simulation period, except for the first $6 \mathrm{~h}$. (d)-(f) As in (a)-(c), but for minimum heating (maximum cooling) rate $\left(\mathrm{K} \mathrm{h}^{-1}\right)$. The red and blue lines in (a) and (d) denote the horizontal locations of the cross sections shown in Figs. 13a-c and 13d-f, respectively, below.

self-consistency checks is due to the large sampling volume in the both checks. ${ }^{5}$

\footnotetext{
${ }^{5}$ For example, for the 16 March 2014 CONUS case, there are 108 total sample times (every $10 \mathrm{~min}$ ) vs 107 when the concurrent time is excluded.
}

\section{Summary}

The Goddard CSH algorithm (Tao et al. 2010) has been recently updated (Lang and Tao 2018). This updated $\mathrm{CSH}$ version uses more and newer simulations (see Table 3) from the GCE model with the new 4ICE scheme (Lang et al. 2014; Tao et al. 2016b) to build its 
(a) NU-WRF simulated original LH (K/hr)

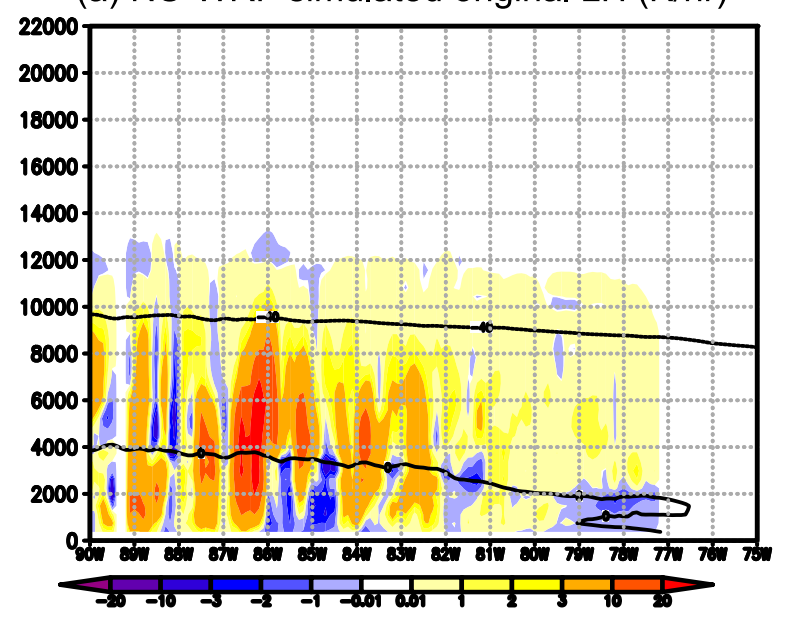

(b) LH (K/hr) retrieved using LUT from this time only

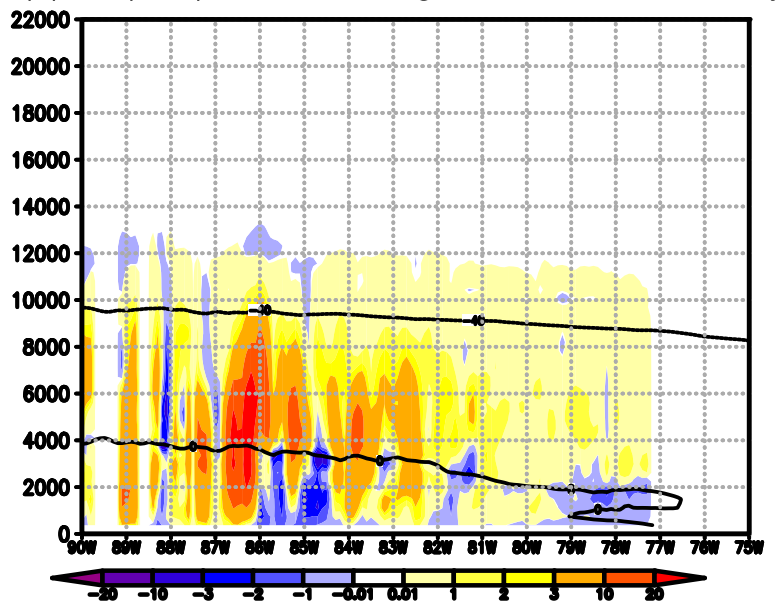

(c) $\mathrm{LH}(\mathrm{K} / \mathrm{hr})$ retrieved using LUT from the whole time

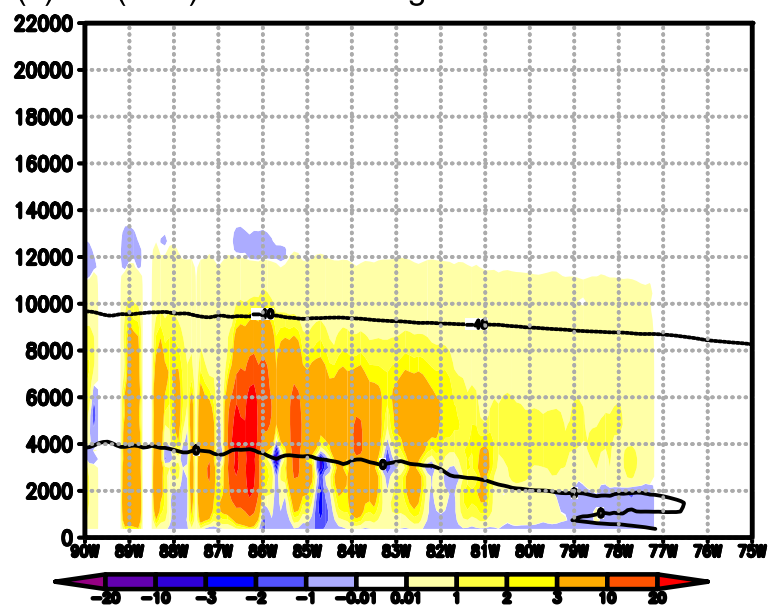

(d) NU-WRF simulated original LH (K/hr)

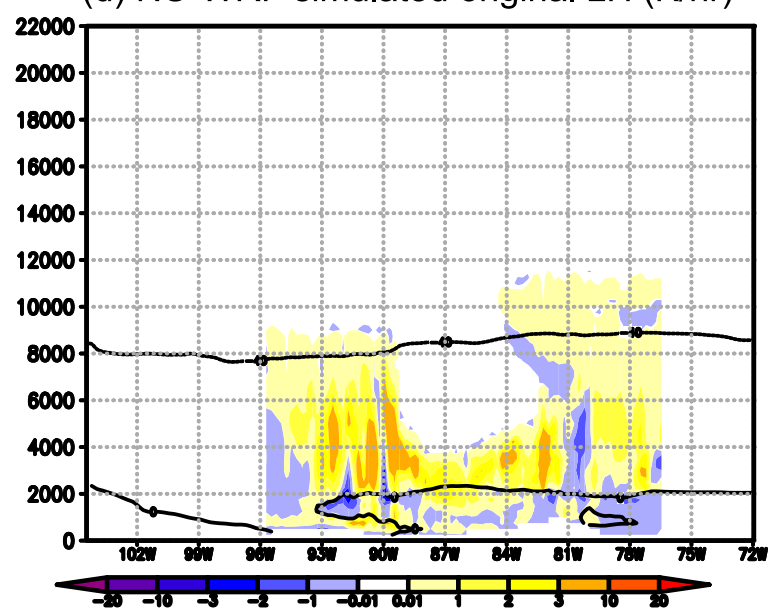

(e) LH (K/hr) retrieved using LUT from this time only

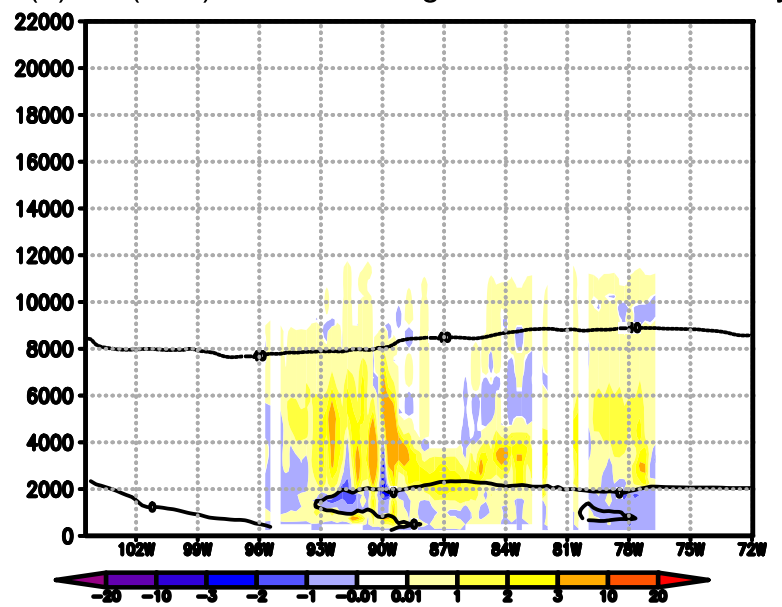

(f) LH (K/hr) retrieved using LUT from the whole time

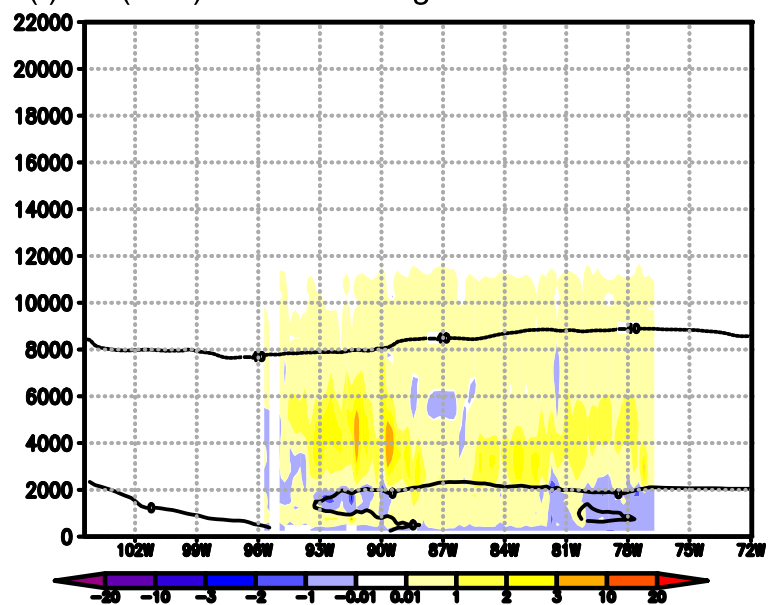

FIG. 13. Vertical cross sections of latent heating/cooling rates and air temperature (contour lines) along the red line shown in Fig. 12a, (a) directly from the NU-WRF simulation at 1800 UTC 16 Mar 2014, (b) retrieved using an LUT based on the NU-WRF simulation results at this time only, and (c) retrieved using an LUT based on the NU-WRF simulation results from every 10 min for the whole 24-h simulation period, except for the first $6 \mathrm{~h}$. (d)-(f) Vertical cross sections along the blue line shown in Fig. 12d. 
(a) NU-WRF simulated original max LH (K/hr)

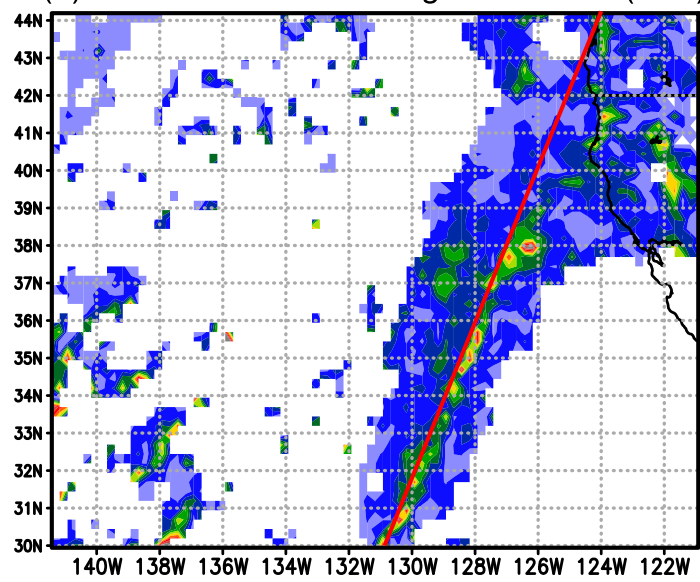

(b) Max LH (K/hr) retrieved using LUT from this time only

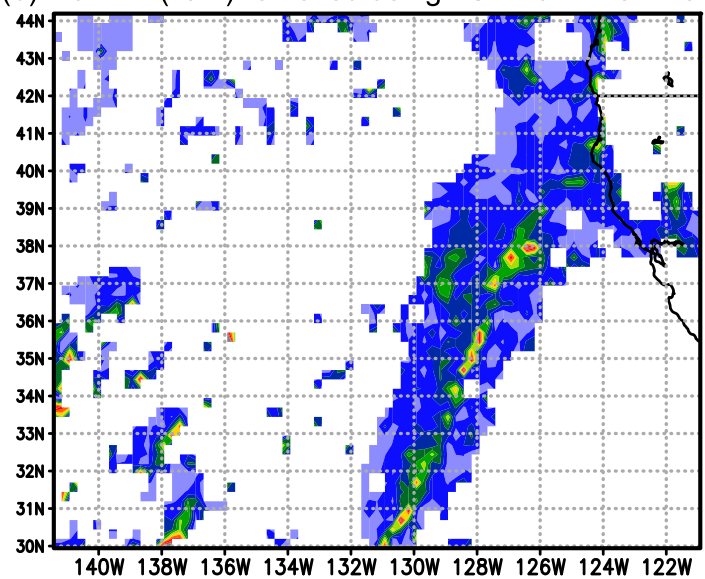

(c) Max LH (K/hr) retrieved using LUT from the whole time

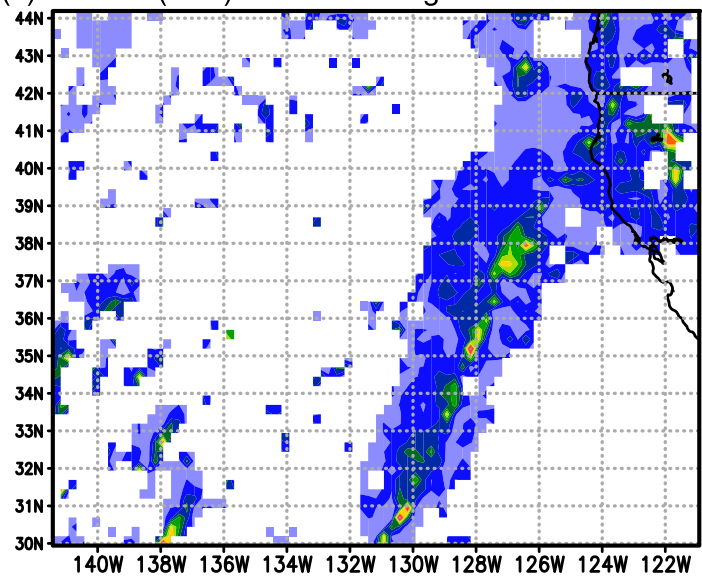

(d) NU-WRF simulated original min LH (K/hr)

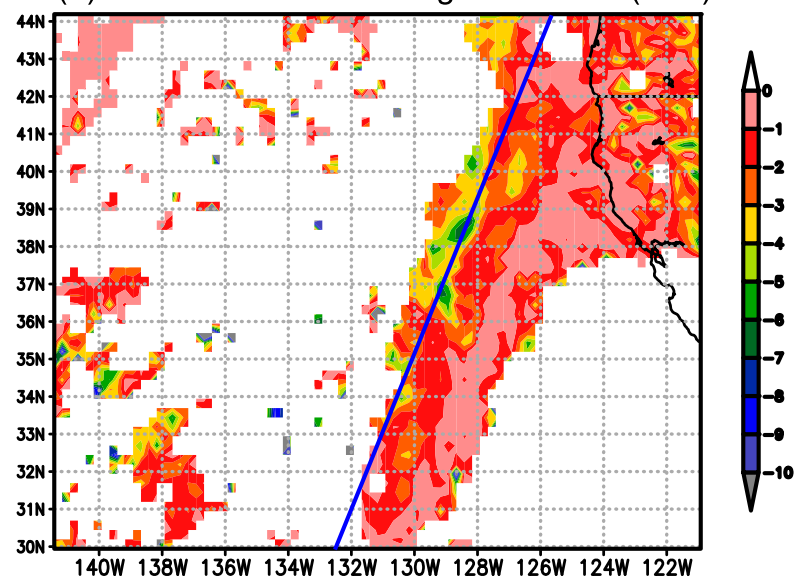

(e) Min LH (K/hr) retrieved using LUT from this time only

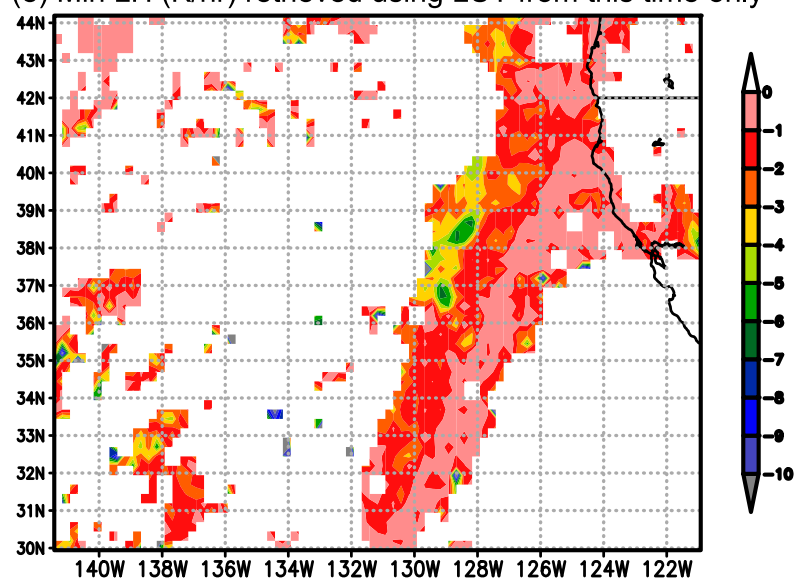

(f) Min LH (K/hr) retrieved using LUT from the whole time

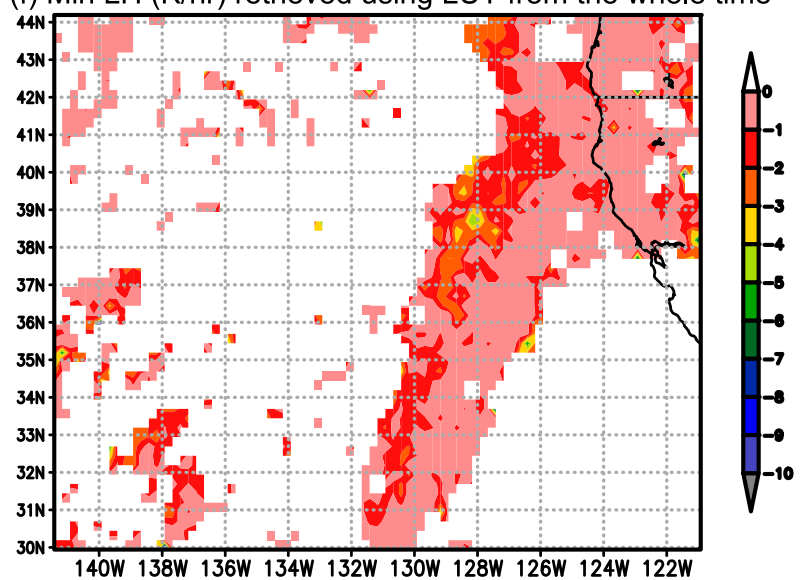

FIG. 14. As in Fig. 12, but for the 6 Feb 2015 CalWater case at 1500 UTC.

LUTs. It also uses two new metrics for mapping the simulated LH structures to the satellite: echo-top heights and low-level echo gradients. To support GPM, the CSH algorithm needs to include $\mathrm{LH}$ profiles associated with higher latitudes (poleward of $35^{\circ} \mathrm{N} / 35^{\circ} \mathrm{S}$ ) and the winter season in its LUTs. Therefore, three different eastern
CONUS and three different West Coast (CalWater) synoptic events are simulated with NU-WRF to build additional LUTs suitable for higher latitudes and coldseason events to expand CSH LH retrievals to those environments. Officially, the $\mathrm{CSH}$ algorithm is used with precipitation products from the GPM DPR-GMI 
(a) NU-WRF simulated original LH (K/hr)

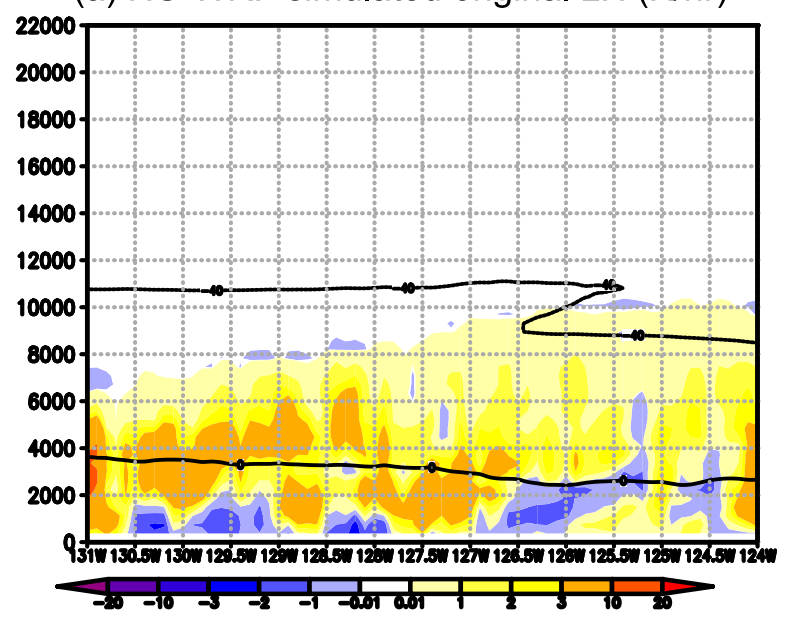

(b) LH (K/hr) retrieved using LUT from this time only

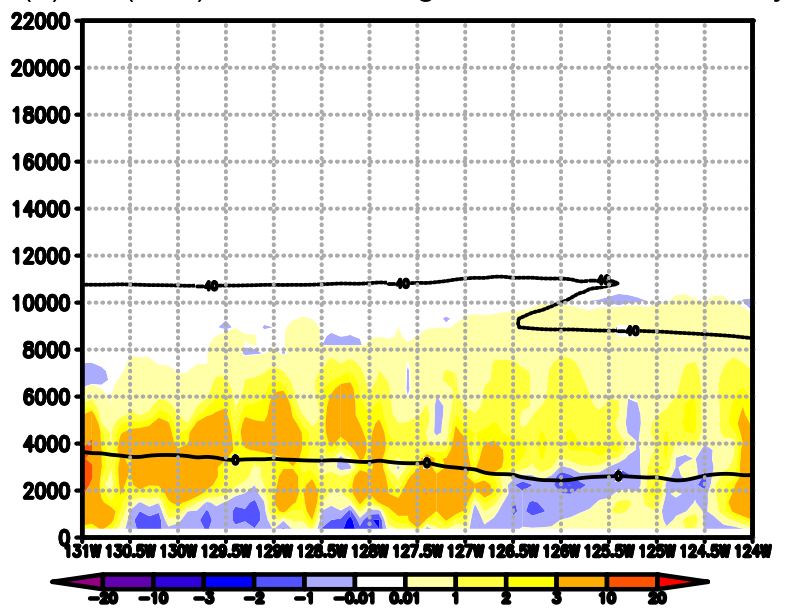

(c) $\mathrm{LH}(\mathrm{K} / \mathrm{hr})$ retrieved using LUT from the whole time

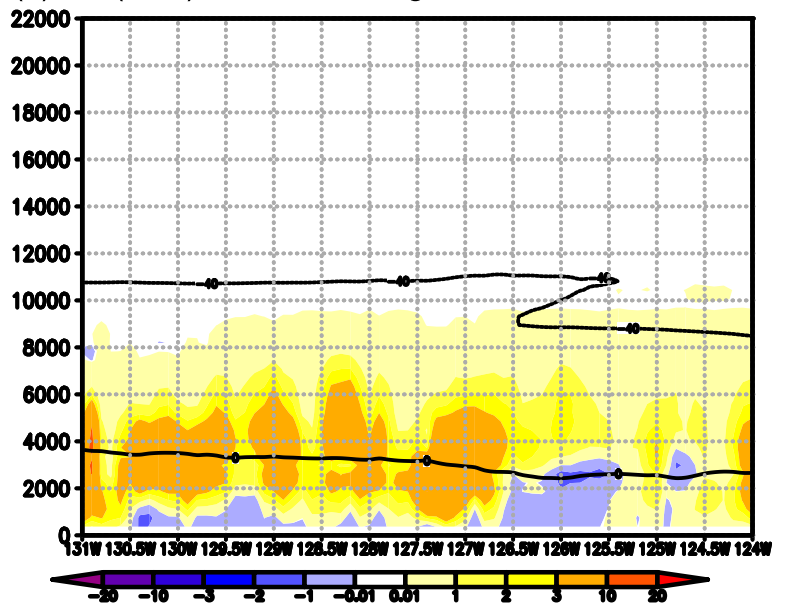

(d) NU-WRF simulated original $\mathrm{LH}(\mathrm{K} / \mathrm{hr})$

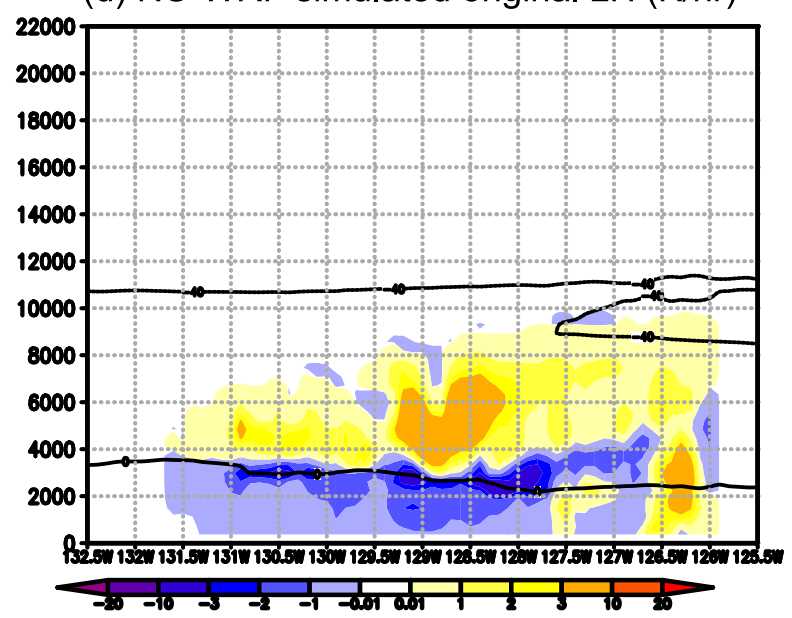

(e) LH (K/hr) retrieved using LUT from this time only

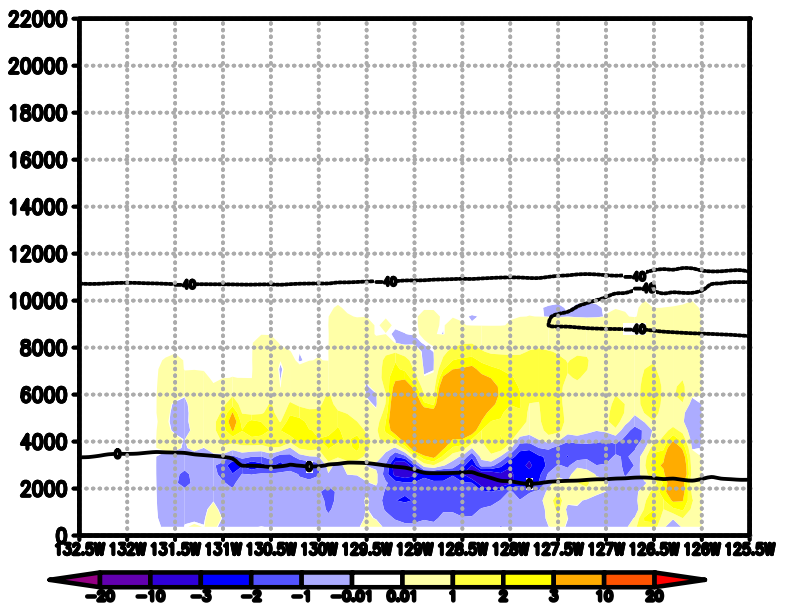

(f) $\mathrm{LH}(\mathrm{K} / \mathrm{hr})$ retrieved using LUT from the whole time

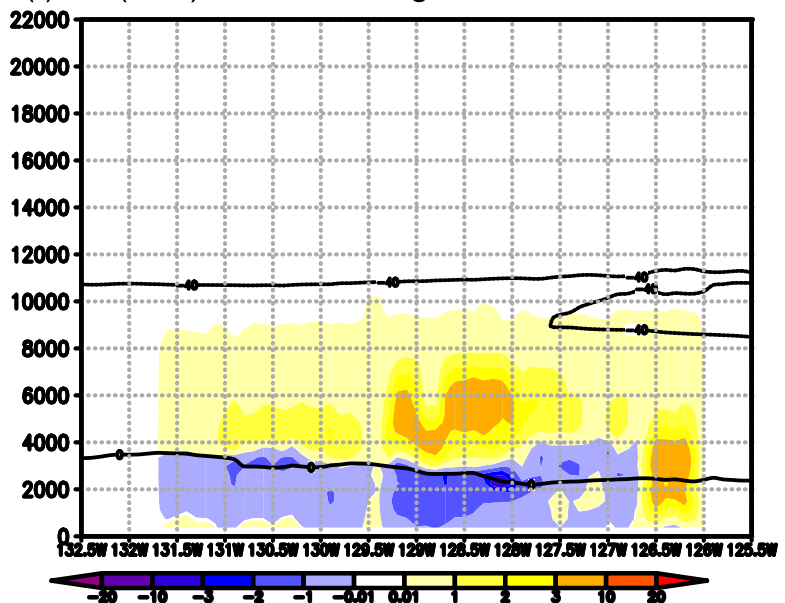

FIG. 15. As in Fig. 13, but for the 6 Feb 2015 CalWater case at 1500 UTC. 
(a) 1800UTC 16 Mar 2014 cross section 1

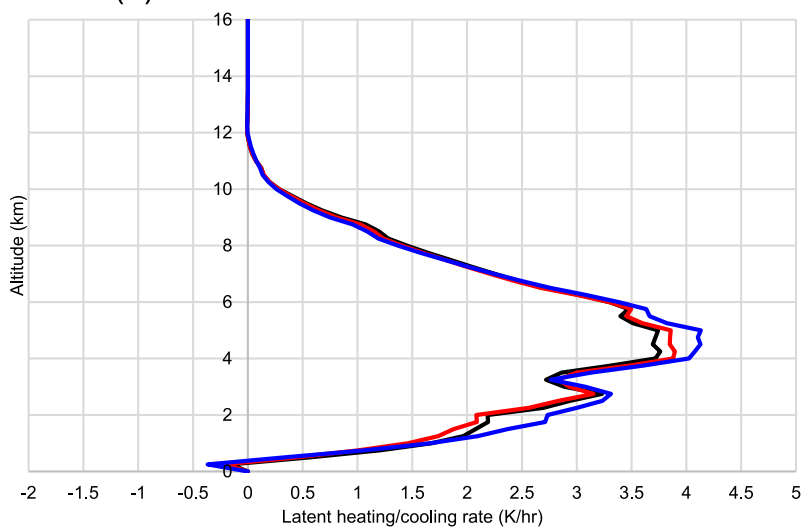

(b) 1800UTC 16 Mar 2014 cross section 2

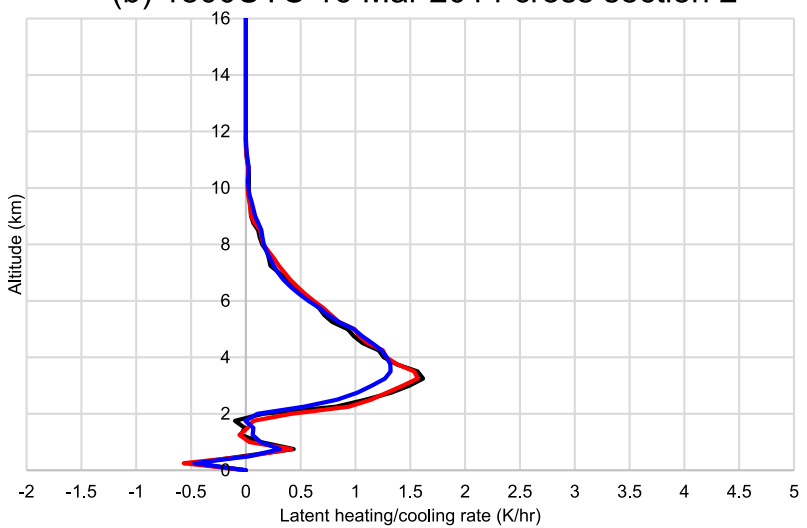

(c) 1800UTC 16 Mar 2014 domain-average

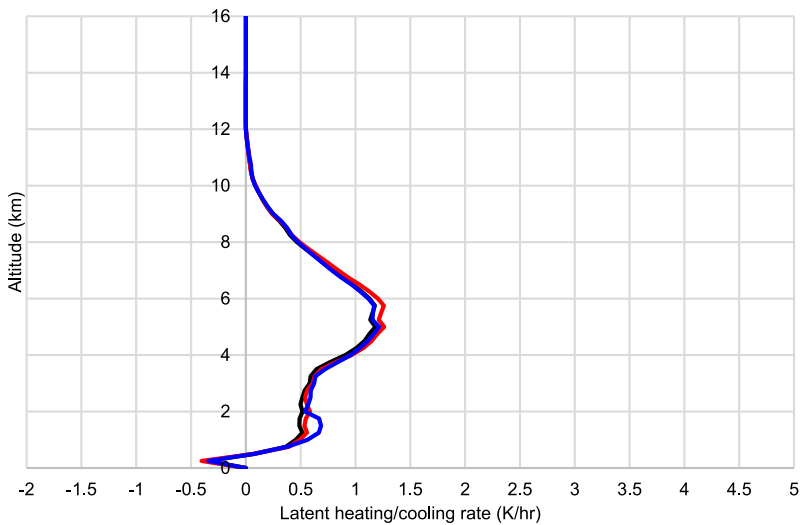

(d) 1500UTC 6 Feb 2015 cross section 1

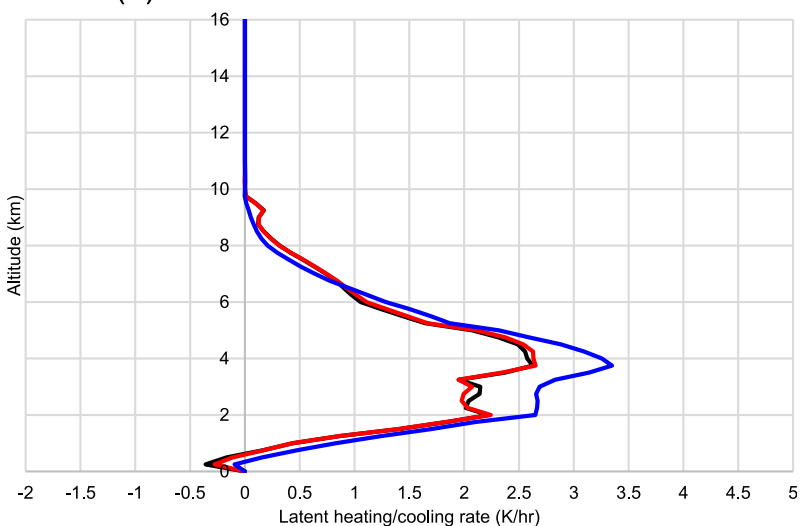

(e) 1500 UTC 6 Feb 2015 cross section 2

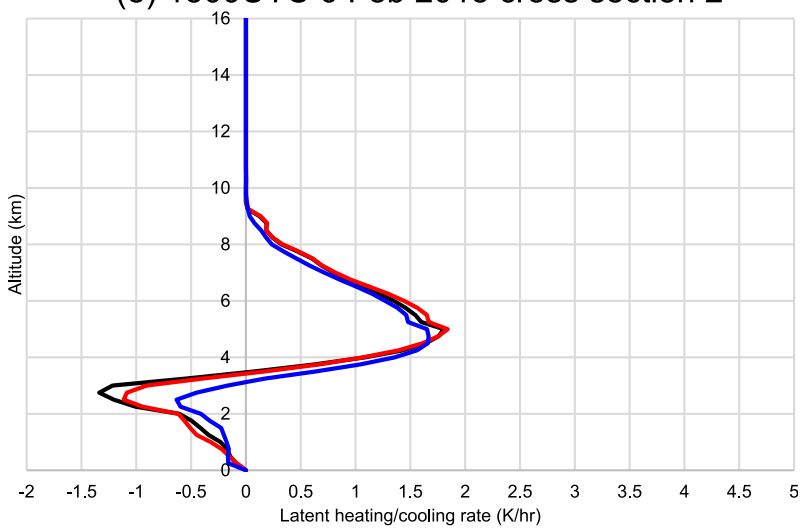

(f) 1500UTC 6 Feb 2015 domain-average

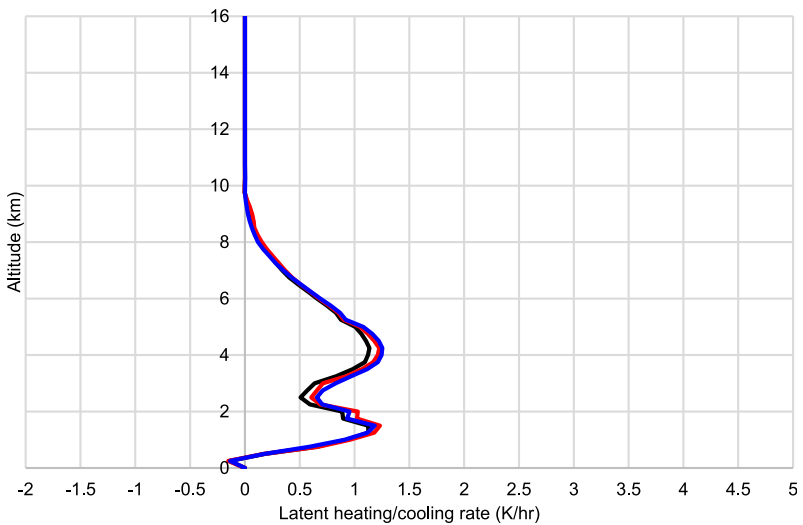

FIG. 16. Vertical profiles of latent heating/cooling rates $\left(\mathrm{K} \mathrm{h}^{-1}\right)$ averaged over the cross sections shown (a) in Figs. 13a-c and (b) in Figs. 13d-f at 1800 UTC 16 Mar 2014 and (c) in Figs. 15a-c and (d) in Figs. 15d-f at 1500 UTC 6 Feb 2015; (e) and (f) are averaged over whole NU-WRF domain for 16 Mar and 6 Feb, respectively. The black, red, and blue lines respectively denote the results derived directly from the NU-WRF simulations, retrieved using an LUT based on the NU-WRF simulation results at that specific time only, and retrieved using an LUT based on NU-WRF simulation results from every $10 \mathrm{~min}$ for the whole simulation period, except for the first $6 \mathrm{~h}$.

combined algorithm (i.e., surface precipitation rates, composite radar reflectivity, freezing-level height, and echo-top height) as input. Therefore, these precipitation properties and their relationship with LH structures are examined using NU-WRF simulations. Consequently, new classifications between LH and precipitation properties are identified and new LUTs are built. A self-consistency check approach is used to examine the performance of the new LUTs. The major highlights are as follows: 
- The NU-WRF-simulated surface precipitation (intensity, pattern, and location) is in very good agreement with NLDAS-2 observed for all three CONUS cases, but the simulated precipitation area is larger than the NLDAS-2 observed, especially over the northern sector of the system in all three cases. For the three CalWater cases, the NU-WRF simulations are in good agreement with the 12-hourly precipitation pattern, orientation, and location relative to IMERG. The amounts are in good overall agreement as well; but the heaviest rainfall amounts within the stronger AR events and just off shore the California coast are underestimated relative to IMERG, and rain is lacking along the southern end of the weaker event. However, the model clearly captures the variation among these three events.

- The results suggest that NU-WRF-simulated precipitation quantities can be used to refine/quantify the relation between latent heating/cooling and precipitation properties (echo-top height, freezing-level height, radar reflectivity, maximum radar reflectivity height, and surface precipitation rate). For example, strong (weak) LH is coincident with high (low) composite radar reflectivity. Strong LH is also coincident with large surface precipitation rates. Stronger LH aloft (above the freezing level) usually coincides with higher radar reflectivity beneath the freezing level. On the other hand, strong cooling (evaporation + melting) is usually located beneath the freezing level. There is also considerable cooling above the freezing level as a result of sublimation. Stronger LH is usually coincident with the higher echo-top heights. However, some of these relationships are not always true. For example, weak LH can be coincident with echo-top heights over $5-6 \mathrm{~km}$. Clearly, there is no unique correlation between $\mathrm{LH}$ profiles and one specific precipitation property. Collectively, LH profiles can be estimated and refined according to the ambient reflectivity/precipitation structures and properties, which provides the basis for the LUTs associated with colder environments.

- LH profiles have characteristics that are usually associated with convective (all heating from the low to upper troposphere) and stratiform (cooling beneath the freezing level and heating aloft) region in the organized convective systems in the new LUTs. These LH profiles are usually associated with high echo-top heights and high (convective) and low (stratiform) surface precipitation rates. Their vertical structures could be characterized by the freezing-level height and maximum radar reflectivity height. In addition, some LH profiles in the new LUTs have characteristics of shallow clouds and midlevel clouds. These profiles are usually associated with low surface precipitation rates and low echo-top heights.
- There are no direct measurements to validate the CSHretrieved LH profiles. Therefore, a self-consistency check approach is used to validate the new LUTs for these winter systems. Two different self-consistency check methods are conducted for one CONUS and one CalWater case. The differences between these two types of self-consistency checks are the LUTs. The first self-consistency check uses an LUT produced at a specific model integration time. The second one uses an LUT produced from the entire model integration, except for the spin-up time. The retrieved LH structures from the first consistency check are in excellent agreement with the model "truth," that is, the actual simulated LH structures for both cases. The retrieved LH structures (level of maximum and minimum heating/cooling) from the second consistency check are quite similar to the truth for both cases, but mean the LH profile is slightly stronger (weaker) than the truth profile for the CONUS (CalWater) case.

New CSH extratropical retrievals using these new higher-latitude LUTs built upon the six NU-WRF simulations of midlatitude cyclones (three oceanic and three continental) are being merged (based on freezing-level height) with retrievals from the updated version of the tropical portion of the algorithm (Lang and Tao 2018) to generate CSH LH estimates over the entire GPM domain (i.e., $67^{\circ} \mathrm{N}-67^{\circ} \mathrm{S}$ ). Also, a close collaboration between the CSH and Japan SLH algorithm teams is taking place in terms of 1) sharing the same cases and 2) comparing the LH structures. For example, the SLH team just received all of the GCEsimulated cases shown in Table 3 that are being used for the latest version of the CSH algorithm. Also, the CSH team will simulate synoptic cases over the Sea of Japan that are being used for the SLH algorithm's LUTs for winter systems. In the near future, the CSH- and SLHderived orbital LH will be compared and their similarities and differences will be characterized.

Acknowledgments. This research was supported by the NASA Precipitation Measuring Mission (PMM) and NASA Energy and Water cycle Study (NEWS). NUWRF is supported by the NASA Modeling, Analysis, and Prediction (MAP) program. The authors are grateful to Drs. R. Kakar, G. S. Jackson, J. Entin, and David Considine at NASA Headquarters for their support of this research. Acknowledgment is also made to the NASA Goddard Space Flight Center and NASA Ames computing centers for the computational resources used in this research. The authors also thank the three anonymous reviewers for their helpful comments, which helped to improve this paper. 


\section{REFERENCES}

Berg, W., T. L'Ecuyer, and J. M. Haynes, 2010: The distribution of rainfall over oceans from spaceborne radars. J. Appl. Meteor. Climatol., 49, 535-543, https://doi.org/10.1175/2009JAMC2330.1.

Chou, M.-D., and M. J. Suarez, 1999: A solar radiation parameterization for atmospheric studies. NASA Tech. Memo. NASA/TM-1999-10460, Vol. 15, 38 pp., http://gmao.gsfc.nasa.gov/ pubs/docs/Chou136.pdf.

- - , X.-Z. Liang, and M. M.-H. Yan, 2001: A thermal infrared radiation parameterization for atmospheric studies. NASA Tech. Rep. NASA/TM-2001-104606, Vol. 19, 54 pp., https:// ntrs.nasa.gov/archive/nasa/casi.ntrs.nasa.gov/20010072848.pdf.

Das, S., D. Johnson, and W.-K. Tao, 1999: Single-column and cloud ensemble model simulations of TOGA COARE convective systems. J. Meteor. Soc. Japan, 77, 803-826, https://doi.org/ 10.2151/jmsj1965.77.4_803.

Fairall, C. W., S. Y. Matrosov, C. R. Williams, and E. J. Walsh, 2018: Estimation of rain rate from airborne Doppler W-band radar in CalWater-2. J. Atmos. Oceanic Technol., 35, 593-608, https://doi.org/10.1175/JTECH-D-17-0025.1.

Grecu, M., and W. S. Olson, 2006: Bayesian estimation of precipitation from satellite passive microwave observations using combined radar-radiometer retrievals. J. Appl. Meteor. Climatol., 45, 416-433, https://doi.org/10.1175/JAM2360.1.

$\longrightarrow,-$ C.-L. Shie, T. L'Ecuyer, and W.-K. Tao, 2009: Combining satellite microwave radiometer and radar observations to estimate atmospheric latent heating profiles. J. Climate, 22, 6356-6376, https://doi.org/10.1175/2009JCLI3020.1.

Houze, R. A., Jr., 1982: Cloud clusters and large-scale vertical motions in the tropics. J. Meteor. Soc. Japan, 60, 396-409, https://doi.org/10.2151/jmsj1965.60.1_396.

Huaman, L., and C. Schumacher, 2018: Assessing the vertical latent heating structure of the east Pacific ITCZ using the CloudSat CPR and TRMM PR. J. Climate, 31, 2563-2577, https://doi.org/ 10.1175/JCLI-D-17-0590.1.

Iguchi, T., and Coauthors, 2012a: Numerical analysis using WRFSBM for the cloud microphysical structures in the C3VP field campaign: Impacts of supercooled droplets and resultant riming on snow microphysics. J. Geophys. Res., 117, D23206, https://doi.org/10.1029/2012JD018101.

— T. Matsui, A. Tokay, P. Kollias, and W.-K. Tao, 2012b: Two distinct modes in one-day rainfall event during MC3E field campaign: Analyses of disdrometer observations and WRFSBM simulation. Geophys. Res. Lett., 39, L24805, https://doi.org/ 10.1029/2012GL053329.

_ - and Coauthors, 2014: WRF-SBM simulations of melting layer structure in mixed-phase precipitation events observed during LPVEx. J. Appl. Meteor. Climatol., 53, 2710-2731, https://doi.org/ 10.1175/JAMC-D-13-0334.1.

- and Coauthors, 2017: Sensitivity of CONUS summer rainfall to the selection of cumulus parameterization schemes in NUWRF seasonal simulations. J. Hydrometeor., 18, 1689-1706, https://doi.org/10.1175/JHM-D-16-0120.1.

Johnson, D. E., W.-K. Tao, J. Simpson, and C.-H. Sui, 2002: A study of the response of deep tropical clouds to large-scale thermodynamic forcing. Part I: Modeling strategies and simulations of TOGA COARE convective systems. J. Atmos. Sci., 59, 3492-3518, https:// doi.org/10.1175/1520-0469(2002)059<3492:ASOTRO >2.0.CO;2.

Johnson, R. H., 1984: Partitioning tropical heat and moisture budgets into cumulus and mesoscale components: Implications for cumulus parameterization. Mon. Wea. Rev., 112, 1590-1601, https:// doi.org/10.1175/1520-0493(1984)112<1590:PTHAMB > 2.0.CO;2.
Kalnay, E., and Coauthors, 1996: The NCEP/NCAR 40-Year Reanalysis Project. Bull. Amer. Meteor. Soc., 77, 437-471, https:// doi.org/10.1175/1520-0477(1996)077<0437:TNYRP>2.0.CO;2.

Lang, S. E., and W.-K. Tao, 2018: The next-generation Goddard convective-stratiform heating algorithm: New tropical and warm-season retrievals for GPM. J. Climate, 31, 5997-6026, https://doi.org/10.1175/JCLI-D-17-0224.1.

J.-D. Chern, D. Wu, and X. Li, 2014: Benefits of a fourth ice class in the simulated radar reflectivities of convective systems using a bulk microphysics scheme. J. Atmos. Sci., 71, 3583-3612, https://doi.org/10.1175/JAS-D-13-0330.1.

Lee, H., D. E. Waliser, R. Ferraro, T. Iguchi, C. D. Peters-Lidard, B. Tian, P. C. Loikith, and D. B. Wright, 2017: Evaluating hourly rainfall characteristics over the U.S. Great Plains in dynamically downscaled climate model simulations using NASA-Unified WRF. J. Geophys. Res. Atmos., 122, 73717384, https://doi.org/10.1002/2017JD026564.

Li, X., and Coauthors, 2018: Evolution of precipitation structure during the November DYNAMO MJO event: Cloudresolving model intercomparison and cross validation using radar observations. J. Geophys. Res. Atmos., 123, 3530-3555, https://doi.org/10.1002/2017JD027775.

Matsui, T., and J. P. Jacob, 2014: User guide: Goddard radiation scheme for NU-WRF, version 2014. NASA Goddard Space Flight Center Doc., 4 pp., https://modelingguru.nasa.gov/servlet/JiveServlet/ previewBody/2547-102-1-6242/UserGuide_Radiation2014.pdf.

, S. Q. Zhang, S. E. Lang, W. K. Tao, C. Ichoku, and C. D. PetersLidard, 2019: Impact of radiation frequency, precipitation radiative forcing, and radiation column aggregation on convectionpermitting West African monsoon simulations. Climate Dyn., https://doi.org/10.1007/s00382-018-4187-2, in press.

Mellor, G. L., and T. Yamada, 1982: Development of a turbulence closure model for geophysical fluid problems. Rev. Geophys., 20, 851-875, https://doi.org/10.1029/RG020i004p00851.

Nelson, E. L., and T. S. L'Ecuyer, 2018: Global character of latent heat release in oceanic warm rain systems. J. Geophys. Res. Atmos., 123, 4797-4817, https://doi.org/10.1002/2017JD027844. , S. M. Saleeby, W. Berg, S. R. Herbener, and S. C. van den Heever, 2016: Toward an algorithm for estimating latent heat release in warm rain systems. J. Atmos. Oceanic Technol., 33, 1309-1329, https://doi.org/10.1175/JTECH-D-15-0205.1.

Peters-Lidard, C. D., and Coauthors, 2015: Integrated modeling of aerosol, cloud, precipitation and land processes at satelliteresolved scales. Environ. Modell. Software, 67, 149-159, https://doi.org/10.1016/j.envsoft.2015.01.007.

Ralph, F. M., and Coauthors, 2016: CalWater field studies designed to quantify the roles of atmospheric rivers and aerosols in modulating U.S. West Coast precipitation in a changing climate. Bull. Amer. Meteor. Soc., 97, 1209-1228, https://doi.org/ 10.1175/BAMS-D-14-00043.1.

Satoh, S., and A. Noda, 2001: Retrieval of latent heating profiles from TRMM radar data. Proc. 30th Int. Conf. on Radar Meteorology, Munich, Germany, Amer. Meteor. Soc., 6.3, http:// ams.confex.com/ams/30radar/techprogram/paper_21763.htm.

Shi, J. J., and Coauthors, 2010: Microphysical properties of the 2022 January 2007 snow events over eastern Canada: Comparison with in situ and satellite observations. J. Appl. Meteor. Climatol., 49, 2246-2266, https://doi.org/10.1175/2010JAMC2282.1.

— , and Coauthors, 2014: Implementation of an aerosol-cloudmicrophysics-radiation coupling into the NASA Unified WRF: Simulation results for the 6-7 August 2006 AMMA special observing period. Quart. J. Roy. Meteor. Soc., 140, 2158-2175, https://doi.org/10.1002/qj.2286. 
Shige, S., Y. N. Takayabu, W.-K. Tao, and D. E. Johnson, 2004: Spectral retrieval of latent heating profiles from TRMM PR data. Part I: Development of a model-based algorithm. J. Appl. Meteor., 43, 1095-1113, https://doi.org/10.1175/15200450(2004)043<1095:SROLHP $>2.0$. CO;2.

and C.-L. Shie, 2007: Spectral retrieval of latent heating profiles from TRMM PR data. Part II: Algorithm improvement and heating estimates over tropical ocean regions. J. Appl. Meteor., 46, 1098-1124, https://doi.org/10.1175/JAM2510.1.

,-- , and,- 2008 : Spectral retrieval of latent heating profiles from TRMM PR data. Part III: Estimating apparent moisture sink profiles over tropical oceans. J. Appl. Meteor. Climatol., 47, 620-640, https://doi.org/10.1175/2007JAMC1738.1.

- _ - S. Kida, W.-K. Tao, X. Zeng, and T. L'Ecuyer, 2009: Spectral retrieval of latent heating profiles from TRMM PR data. Part IV: Comparisons of lookup tables from two- and three-dimensional simulations. J. Climate, 22, 5577-5594, https://doi.org/10.1175/2009JCLI2919.1.

Skamarock, W. C., and Coauthors, 2008: A description of the Advanced Research WRF version 3. NCAR Tech. Note NCAR/ TN-475+STR, 113 pp., https://doi.org/10.5065/D68S4MVH.

Steiner, M., R. A. Houze, and S. E. Yuter, 1995: Climatological characterization of three-dimensional storm structure from operational radar and rain gauge data. J. Appl. Meteor., 34, 1978-2007, https://doi.org/10.1175/1520-0450(1995)034<1978:CCOTDS > 2.0.CO;2.

Tao, W.-K., J. Simpson, S. Lang, M. McCumber, R. Adler, and R. Penc, 1990: An algorithm to estimate the heating budget from vertical hydrometeor profiles. J. Appl. Meteor., 29, 1232-1244, https://doi.org/10.1175/1520-0450(1990)029<1232:AATETH> 2.0.CO;2.

_ , S. Lang, J. Simpson, and R. Adler, 1993: Retrieval algorithms for estimating the vertical profiles of latent heat release: Their applications for TRMM. J. Meteor. Soc. Japan, 71, 685-700, https://doi.org/10.2151/jmsj1965.71.6_685.

,,,--- W. S. Olson, D. Johnson, B. Ferrier, C. Kummerow, and R. Adler, 2000: Retrieving vertical profiles of latent heat release in TOGA COARE convective systems using a cloud resolving model, SSM/I and radar data. J. Meteor. Soc. Japan, 78, 333-355, https://doi.org/10.2151/jmsj1965.78.4_333.

__, and Coauthors, 2001: Retrieved vertical profiles of latent heating release using TRMM rainfall products for February 1998. J. Appl. Meteor., 40, 957-982, https://doi.org/10.1175/ 1520-0450(2001)040<0957:RVPOLH >2.0.CO;2.

- C.-L. Shie, R. Johnson, S. Braun, J. Simpson, and P. E. Ciesielski, 2003: Convective systems over the South China Sea: Cloud resolving model simulations. J. Atmos. Sci., 60, 2929-2956, https:// doi.org/10.1175/1520-0469(2003)060<2929:CSOTSC >2.0.CO;2.

_ D. Johnson, C.-L. Shie, and J. Simpson, 2004: Atmospheric energy budget and large-scale precipitation efficiency of convective systems during TOGA COARE, GATE, SCSMEX and ARM: Cloud-resolving model simulations. J. Atmos. Sci., 61, 2405-2423, https://doi.org/10.1175/1520-0469(2004)061<2405: TAEBAL $>2.0 . \mathrm{CO} ; 2$.

— , and Coauthors, 2006: Retrieval of latent heating from TRMM measurements. Bull. Amer. Meteor. Soc., 87, 15551572, https://doi.org/10.1175/BAMS-87-11-1555.

—, S. Lang, X. Zeng, S. Shige, and Y. Takayabu, 2010: Relating convective and stratiform rain to latent heating. J. Climate, 23, 1874-1893, https://doi.org/10.1175/2009JCLI3278.1.

— , and Coauthors, 2013: Precipitation intensity and variation during MC3E: A numerical modeling study. J. Geophys. Res. Atmos., 118, 7199-7218, https://doi.org/10.1002/jgrd.50410.
— - and Coauthors, 2016a: TRMM latent heating retrieval: Applications and comparison with field campaigns and large-scale analyses. Multiscale Convection-Coupled Systems in the Tropics: A Tribute to Dr. Yanai, Meteor. Monogr., No. 56, Amer. Meteor. Soc., https://doi.org/10.1175/AMSMONOGRAPHS-D-15-0013.1.

—, D. Wu, S. Lang, J.-D. Chern, C. Peters-Lidard, A. Fridlind, and T. Matsui, 2016b: High-resolution NU-WRF simulations of a deep convective-precipitation system during MC3E: Further improvements and comparisons between Goddard microphysics schemes and observations. J. Geophys. Res. Atmos., 121, 1278-1305, https://doi.org/10.1002/2015JD023986.

Tian, B., and Coauthors, 2017: Development of a model performance metric and its application to assess summer precipitation over the U.S. Great Plains in downscaled climate simulations. J. Hydrometeor., 18, 2781-2799, https://doi.org/ 10.1175/JHM-D-17-0045.1.

Wolff, D. B., D. A. Marks, E. Amitai, D. S. Silberstein, B. L. Fisher, A. Tokay, J. Wang, and J. L. Pippitt, 2005: Ground validation for the Tropical Rainfall Measuring Mission (TRMM). J. Atmos. Oceanic Technol., 22, 365-380, https://doi.org/10.1175/JTECH1700.1.

Wu, D., C. Peters-Lidard, W.-K. Tao, and W. Petersen, 2016: valuation of NU-WRF real-time rainfall forecast for IFloodS. J. Hydrometeor. 17, 1317-1335, https://doi.org/10.1175/JHM-D-15-0134.1.

Xia, Y., and Coauthors, 2012: Continental-scale water and energy flux analysis and validation for the North American Land Data Assimilation System project phase 2 (NLDAS-2): 1. Intercomparison and application of model products. J. Geophys. Res., 117, D03109, https://doi.org/10.1029/2011JD016048.

Yanai, M., S. Esbensen, and J. Chu, 1973: Determination of average bulk properties of tropical cloud clusters from large-scale heat and moisture budgets. J. Atmos. Sci., 30, 611-627, https:// doi.org/10.1175/1520-0469(1973)030<0611:DOBPOT>2.0.CO;2.

Yang, S., and E. A. Smith, 1999a: Four-dimensional structure of monthly latent heating derived from SSM/I satellite measurements. J. Climate, 12, 1016-1037, https://doi.org/10.1175/ 1520-0442(1999)012<1016:FDSOML > 2.0.CO;2.

— , and _ 1999b: Moisture budget analysis of TOGA COARE area using SSM/I-retrieved latent heating and large-scale $Q_{2}$ estimates. J. Atmos. Oceanic Technol., 16, 633-655, https://doi.org/ 10.1175/1520-0426(1999)016<0633:MBAOTC $>2.0$. CO;2.

$\longrightarrow$, and - 2000: Vertical structure and transient behavior of convective-stratiform heating in TOGA COARE from combined satellite-sounding analysis. J. Appl. Meteor., 39, 1491-1513, https:// doi.org/10.1175/1520-0450(2000)039<1491:VSATBO > 2.0.CO;2.

Zeng, X., and Coauthors, 2007: Evaluating clouds in long-term cloudresolving model simulations with observational data. J. Atmos. Sci., 64, 4153-4177, https://doi.org/10.1175/2007JAS2170.1.

—, W.-K. Tao, S. Lang, A. Y. Hou, M. Zhang, and J. Simpson, 2008: On the sensitivity of atmospheric ensembles to cloud microphysics in long-term cloud-resolving model simulations. J. Meteor. Soc. Japan, 86A (Special Issue), 45-65, https://doi.org/10.2151/jmsj.86A.45. - and Coauthors, 2009: The indirect effect of ice nuclei on atmospheric radiation. J. Atmos. Sci., 66, 41-61, https://doi.org/ 10.1175/2008JAS2778.1.

— - W.-K. Tao, S. Powell, R. Houze Jr., P. Ciesielski, N. Guy, H. Pierce, and T. Matsui, 2013: A comparison of water budgets between clouds from AMMA and TWP-ICE. J. Atmos. Sci. 70, 487-503, https://doi.org/10.1175/JAS-D-12-050.1.

Zhang, S. Q., T. Matsui, S. Cheung, M. Zupanski, and C. Peters-Lidard, 2017: Impact of assimilated precipitation-sensitive radiances on the NU-WRF simulation of the West African Monsoon. Mon. Wea Rev., 145, 3881-3900, https://doi.org/10.1175/MWR-D-16-0389.1. 